\title{
The sodium-activated potassium channel Slack is required for optimal cognitive flexibility in mice
}

\author{
Anne E. Bausch, ${ }^{1}$ Rebekka Dieter, ${ }^{1}$ Yvette Nann, ${ }^{1}$ Mario Hausmann, ${ }^{1}$ Nora Meyerdierks, ${ }^{1}$ \\ Leonard K. Kaczmarek, ${ }^{2,3}$ Peter Ruth, ${ }^{1}$ and Robert Lukowski ${ }^{1}$ \\ ${ }^{1}$ Pharmakologie, Toxikologie und Klinische Pharmazie, Institut für Pharmazie, 72076 Tübingen, Germany; ${ }^{2}$ Department \\ of Pharmacology, ${ }^{3}$ Department of Cellular and Molecular Physiology, Yale University School of Medicine, New Haven, \\ Connecticut 06520, USA
}

\begin{abstract}
Kcntl encoded sodium-activated potassium channels (Slack channels) are highly expressed throughout the brain where they modulate the firing patterns and general excitability of many types of neurons. Increasing evidence suggests that Slack channels may be important for higher brain functions such as cognition and normal intellectual development. In particular, recent findings have shown that human Slack mutations produce very severe intellectual disability and that Slack channels interact directly with the Fragile $X$ mental retardation protein (FMRP), a protein that when missing or mutated results in Fragile X syndrome (FXS), the most common form of inherited intellectual disability and autism in humans. We have now analyzed a recently developed Kcnt 1 null mouse model in several behavioral tasks to assess which aspects of memory and learning are dependent on Slack. We demonstrate that Slack deficiency results in mildly altered general locomotor activity, but normal working memory, reference memory, as well as cerebellar control of motor functions. In contrast, we find that Slack channels are required for cognitive flexibility, including reversal learning processes and the ability to adapt quickly to unfamiliar situations and environments. Our data reveal that hippocampal-dependent spatial learning capabilities require the proper function of Slack channels.
\end{abstract}

[Supplemental material is available for this article.]

Sodium-activated potassium $\left(K_{\mathrm{Na}}\right)$ channels are predominantly expressed in neuronal tissue (Bhattacharjee et al. 2002, 2003, 2005; Yuan et al. 2003; Brown et al. 2008) where they are involved in neuronal excitability, burst firing, adaptation of firing rate and, at least in some cell types, Slack contributes to the resting membrane potential (Bhattacharjee and Kaczmarek 2005; Kaczmarek 2013). Although several recent studies provide increasing evidence that $K_{\mathrm{Na}}$ channels are active under physiological conditions (Budelli et al. 2009; Hage and Salkoff 2012), their precise functions in vivo are still speculative. Particularly, the high values for half-maximal activation of $K_{\mathrm{Na}}$ channels by intracellular sodium $\left(\mathrm{EC}_{50}\right)$ (Bhattacharjee et al. 2003; Yuan et al. 2003) have questioned the roles of Slack channels in a physiological setting. So far, two highly related genes encoding sodium-activated potassium channels have been identified: Slack is the product of the Kcnt1 gene (Slo2.2) (Yuan et al. 2003) and Kcnt2 encodes Slick channels (Slo2.1) (Bhattacharjee et al. 2003). Evidence for at least five Slack isoforms that differ in kinetic of activation, frequency of subconductance states, and in their capability to form Slack/Slick heteromers (Brown et al. 2008) may at least in part explain the diversity of native $K_{\mathrm{Na}}$ channels (Dryer 1994; Bhattacharjee and Kaczmarek 2005). Slack activity is regulated by a variety of signaling pathways, involving protein kinase $\mathrm{C}$ or $\mathrm{A}$ as well as endogenous modulators such as $\mathrm{NAD}^{+}$, estradiol, and $\mathrm{PIP}_{2}$ (Kaczmarek 2013). In addition, recent studies have demonstrated a direct interaction between Slack channels and the Fragile X mental retarCorresponding authors: robert.lukowski@uni-tuebingen.de; peter
.ruth@uni-tuebingen.de

Article is online at http://www.learnmem.org/cgi/doi/10.1101/Im.037820.114. dation protein (FMRP) (Brown et al. 2010; Zhang et al. 2012). FMRP is an RNA-binding protein that mediates the transport of specific target mRNAs to synapses where it regulates local stimulus-dependent translation (Bakker and Oostra 2003; Bear et al. 2004). Binding of FMRP to the C-terminus of Slack increases the open probability of the channel, and suppresses the occurrence of subconductance states (Brown et al. 2010). Silencing of FMR1, the human gene encoding FMRP, leads to the Fragile X syndrome (FXS), the most common inherited form of mental retardation and autism (Pfeiffer and Huber 2009). Accordingly, Fmr1 knockout mice, a model for human FXS, exhibit several behavioral abnormalities including habituation deficits in the open field, increased locomotor activity and mild learning deficits (The Dutch-Belgian Fragile X Consortium et al. 1994; D'Hooge et al. 1997; Van Dam et al. 2000; Bakker and Oostra 2003; Kooy 2003; Udagawa et al. 2013). It is unclear, however, whether loss of FMRP modulation of Slack activity (Brown et al. 2010) is, at least in part, responsible for the phenotype of Fmr1 knockout mice and related FXS symptoms. Besides the interplay between FMRP and Slack, FMRP seems to affect the expression and activity of a variety of other potassium channels including Kv3.1, Kv4.2, HCN1, and BK (Gross et al. 2011; Lee et al. 2011; Brager et al. 2012; Deng et al. 2013) and increasing evidence suggests that some aspects of

(C) 2015 Bausch et al. This article is distributed exclusively by Cold Spring Harbor Laboratory Press for the first 12 months after the full-issue publication date (see http://learnmem.cshlp.org/site/misc/terms.xhtml). After 12 months, it is available under a Creative Commons License (AttributionNonCommercial 4.0 International), as described at http://creativecommons. org/licenses/by-nc/4.0/. 
the FXS in humans are also linked to alterations in ion channel functions (Lee and Jan 2012; Zhang et al. 2014; Guglielmi et al. 2015). Interestingly, the potassium channels related to FMRP seem to be important factors for learning processes, for example, Kv4.2 and HCN1 deficient mice exhibit spatial learning (Lockridge and Yuan 2011) and working memory deficits (Thuault et al. 2013), respectively. Along the same lines, the role of $\mathrm{Ca}^{2+}$. and voltage-activated potassium channels of big-conductance (BKs), which are highly related to Slack, have been well established in hippocampal-dependent learning tasks and memory (Matthews et al. 2008; Typlt et al. 2013). The relevance of neuronal Slack channels in behavioral functions, motor skills, or learning and memory processes in vivo is unclear, but recent studies on a series of gain-of-function mutations in the human Slack channel gene all revealed severe intellectual disability and developmental delay coupled to different early-onset epileptic syndromes in affected patients, suggesting that Slack may indeed play an important role in cognition and intellectual development (Aminkeng 2012; Barcia et al. 2012; Heron et al. 2012; Kaczmarek 2013; Kim and Kaczmarek 2014; Kim et al. 2014; Martin et al. 2014).

To test whether expression of Slack channels is required for spatial memory or motor performance, we have now studied recently generated Kcnt1 null mice (Slack KOs) (Lu et al. 2015), and compared their behavior with that of age-matched wild-type (WT) mice. Our data suggest that complex learning processes, including reversal learning in the Morris water maze (MWM) task, locomotor activity, and coping with unfamiliar environments and situations require endogenous Slack channels.

\section{Results}

\section{Slack channels are expressed in the cerebellum and hippocampal formation}

Information about the distribution of Slack channels in different brain regions is not consistent among different reports because in situ hybridization or immunocytochemistry with antibodies directed against different parts of the Slack protein were performed (Joiner et al. 1998; Bhattacharjee et al. 2002; Brown et al. 2008). Our qRT-PCRbased comparison of WT and Slack KO tissue samples confirmed that Slack transcripts are not evenly distributed in mouse brain. High Slack mRNA levels were detected in the cerebellum, whereas the amount of Slack transcripts in the hippocampal formation was about 25fold lower (Fig. 1A). We included Slick specific primers in this analysis to exclude possible up-regulation of Kcnt2derived mRNA on the Slack null background. Importantly, these mRNA analyses correlated well with presence of total Slack protein in the respective brain regions of WT mice (Fig. 1B). To get further insights into the cellular expression patterns of Slack in the cerebellum (Fig. 1C,D) and the hippocampus (Fig. 1E,F), we used the previously described SlackB-antibody on WT and Slack KO brain cryosections (Bhattacharjee et al. 2002). We found high Slack-B immunoreactivity in the granular layer (gr) of the cerebellum, lower immunoreactivity in the cerebellar molecular layer $(\mathrm{ml})$ that contains the axons and dendrites of granular cells and Purkinje neurons, respectively, and no Slack-B expression was found in the Purkinje cell somata (Fig. 1C). In the hippocampus, Slack-B was expressed in the stratum lacunosum moleculare (slm) of the CA regions and in the molecular (mo) as well as the polymorph layer (po) of the dentate gyrus, whereas almost no Slack-B expression was observed in the granular layer of the dentate gyrus (gl) and the pyramidal layers (pl) of CA1 and CA3 (Fig. 1E). We also found high Slack-B expression in the subiculum, the relay station of the hippocampal formation (data not shown). The immunohistochemical analyses were reproduced using an in-house generated Slack antibody that detects all Slack isoforms (Supplemental Fig. 1), showing no specific staining in cerebellum or hippocampus sections obtained from Slack KO mice.

\section{Slack-deficient mice show normal motor functions}

High Slack expression in the cerebellum may point to a previously underestimated role of Slack channels in motor coordination. As behavioral testing requires mice with normal motor function, we tested our Slack mutants for potential motor coordination deficits. First, we analyzed the foot print patterns of Slack KO and WT mice in a narrow corridor (Fig. 2A-C). Neither stride width, overlap precision of the paws nor stride length were different between the two genotypes, allowing us to test the motor performance of Slack mutants in more complicated tasks. We therefore evaluated the abilities of Slack KOs to balance on squared and round beams of decreasing diameter (Fig. 2D). Again, these tasks revealed no differences between both genotypes, indicating that fine motor coordination and balance capabilities do not require functional Slack channels (Fig. 2E-G). However, Slack KOs needed more time to cross the squared $20 \mathrm{~mm}$ beam (Fig. 2G), whereas with increasing difficulty this difference disappeared. As this difference in performance originated from a higher number of rests and was not
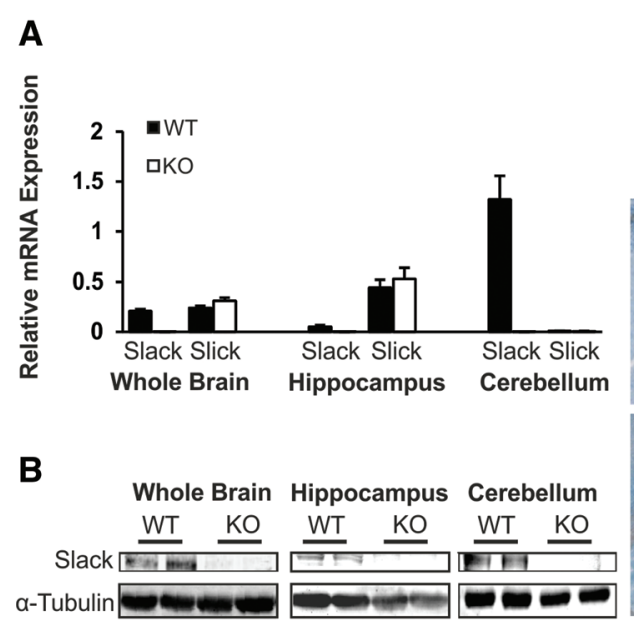

Figure 1. Slack expression in cerebellum and hippocampus. (A) Quantitative RT-PCR showed high Slack mRNA levels in the cerebellum $(n=6)$ and lower levels in the hippocampus $(n=3)$ of WT mice, whereas Slack transcripts were not detectable in the respective brain regions derived from Slack null mutants $(n=2-3)$ and Slack deficiency did not alter Slick mRNA abundance $(n=2-6)$. HPRT mRNA levels were used as a reference to normalize the data. All data are means + SEM. (B) Western blot analyses of membrane enriched protein lysates confirmed absence of the Slack channel proteins in different Slack KO brain regions. (C) Immunohistochemical stainings (blue) confirmed high Slack-B expression in the cerebellar granular ( $\mathrm{gr}$ ) and molecular layer (ml) of WT animals, whereas $(D)$ Slack-B is not detectable in cerebellar sections of Slack KOs. $(E)$ In the hippocampus of WT mice high Slack-B immunoreactivity was found in the stratum-lacunosum moleculare (slm) of the CA subfields and the molecular layer (mo) as well as the polymorph layer (po) of the dentate gyrus. $(F)$ No specific Slack-B staining was found in the hippocampal formation of Slack KO mice (( $\mathrm{gl})$ granular layer of the dentate gyrus, (pl) pyramidal layer of CA1). Scale bars, $200 \mu \mathrm{m}$. 

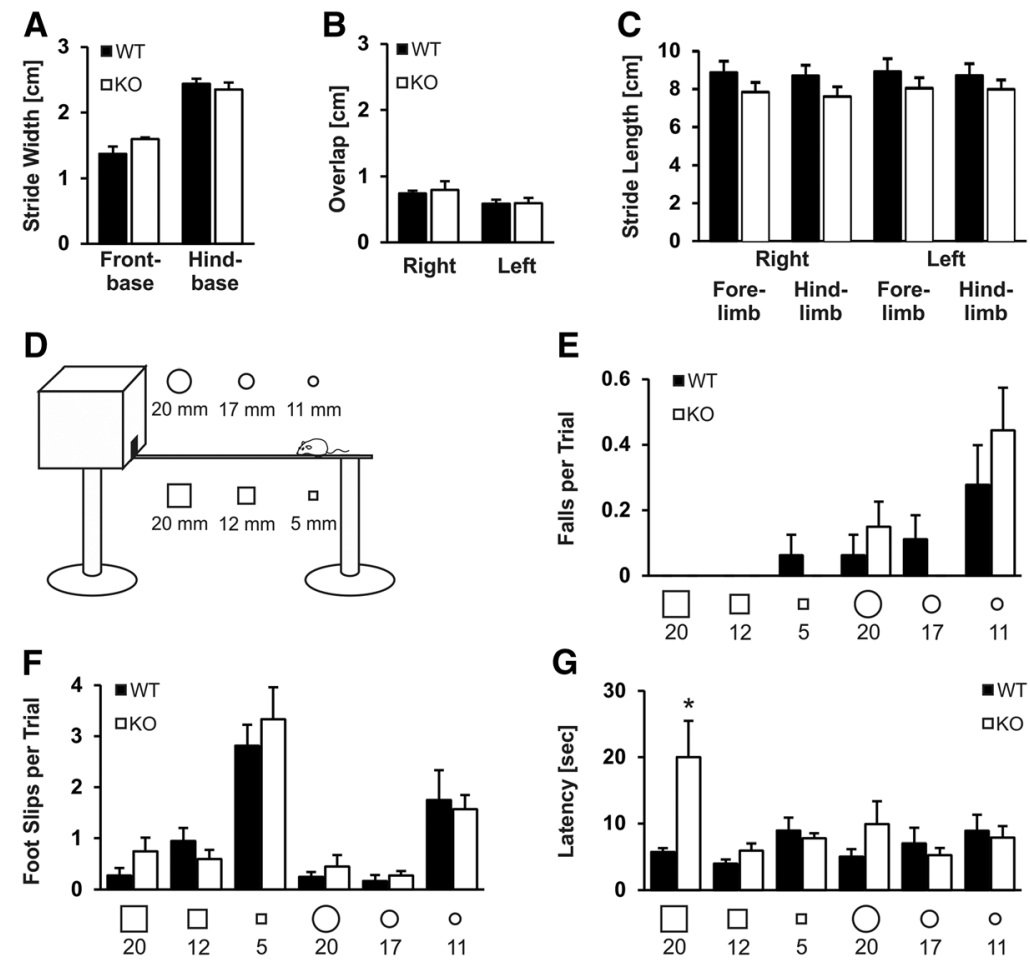

Figure 2. Motor coordination is normal in Slack KOs but Slack-deficient mice show an altered motivation phenotype in an elevated-beam walk test. Foot print analyses revealed no differences in $(A)$ stride width, $(B)$ overlap of the front paw and the ipsilateral hind paw, and (C) stride length between WT $(n=$ $5)$ and Slack-deficient mice $(n=5)$. (D) Schematic view of the beam walk apparatus. (E) Number of falls and $(F)$ foot slips with the hind limbs did not differ between WT $(n=10)$ and Slack KOs $(n=9)$. (G) Mean latency to cross the squared beam with $20 \mathrm{~mm}$ diameter was significantly increased in Slack KOs, but this difference in performance disappeared as the task was getting more difficult, i.e., when the mice crossed a beam with smaller or round diameter. All data are presented as mean + SEM. $\left(^{*}\right)$ $P<0.05$ indicating significant difference between genotypes.

due to a reduced speed of Slack KOs running over the beam, we conclude that motor functions of Slack-deficient mice are normal but rather motivation or the ability to adapt quickly to new situations or environments may be altered. The absence of any motor coordination deficits is in line with our previous study showing that lack of Slack does not affect the performance on an accelerating rotarod (Lu et al. 2015).

\section{Slack KO mice exhibit lower overall locomotor activity, altered explorative behavior and an atypical initial response in an open field}

Slack KO and WT mice were subjected to an open field to test their explorative motivation and spontaneous locomotor activity. When placed in the middle of the circular open field, Slack-deficient mice hold their starting position for a longer period of time as compared with age- and litter-matched WT mice. In consequence, latency of Slack KOs to enter the border area for the first time was significantly increased (Fig. 3A) and Slack KOs spent significantly less time in the border zone of the open field during the first $5 \mathrm{~min}$ (Fig. 3B). These differences between the genotypes were only apparent during the initial phase of the test. After the first 5 min, however, animals of both genotypes spent $\sim 90 \%$ of their total time in the border area (Fig. 3B). This difference in the initial response to the novel environment is also reflected by a decreased explorative behavior of Slack KOs during the first $5 \mathrm{~min}$. WT animals intensively explored the new environment by rearing up at anxiety levels (Choleris et al. 2001; Prut and Belzung 2003; Blizard et al. 2007; Gould et al. 2009), we reasoned that Slack may play a role in setting the threshold level of baseline anxietylike behaviors. To further test this hypothesis, we performed a dark-light-box test as a more direct measure of mouse anxiety. In the dark-light-box test Slack KOs showed a tendency for a preference for the lit compartment (Fig. 3E) and a significant increase in latency to enter the dark compartment for the first time (Fig. $3 \mathrm{~F})$, whereas WT animals, as expected, spent $>50 \%$ of the test period in the dark compartment (Fig. 3E). Together, the decrease in anxiety-like behavior in Slack KOs in the dark-light box was well in line with the increase in center time of the mutants during the early phase of the open field test (Fig. 3A,B).

\section{Decreased and nonsystematic explorative behavior of Slack-deficient mice in an elevated-plus-maze}

To investigate the anxiety phenotype of Slack KOs in more detail, we subjected Slack KO and WT mice to the elevated-plus-maze test. This test is based on the conflict between the innate preference of mice to stay in protected areas and their explorative drive that encourages them to enter and explore the unprotected arms of the maze despite their intrinsic tendency to avoid all open and/ or elevated places. Slack-deficient mice on average spent more time on the open arms of the elevated-plus-maze than their WT counterparts (Supplemental Fig. 3A), but this clear tendency missed reaching the significance level (WT: $5.9 \% \pm 1.6$; KO: $27.2 \% \pm 11.0 ; P=0.08$ ) because of a considerable variability 
A

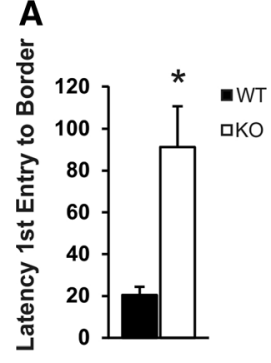

B
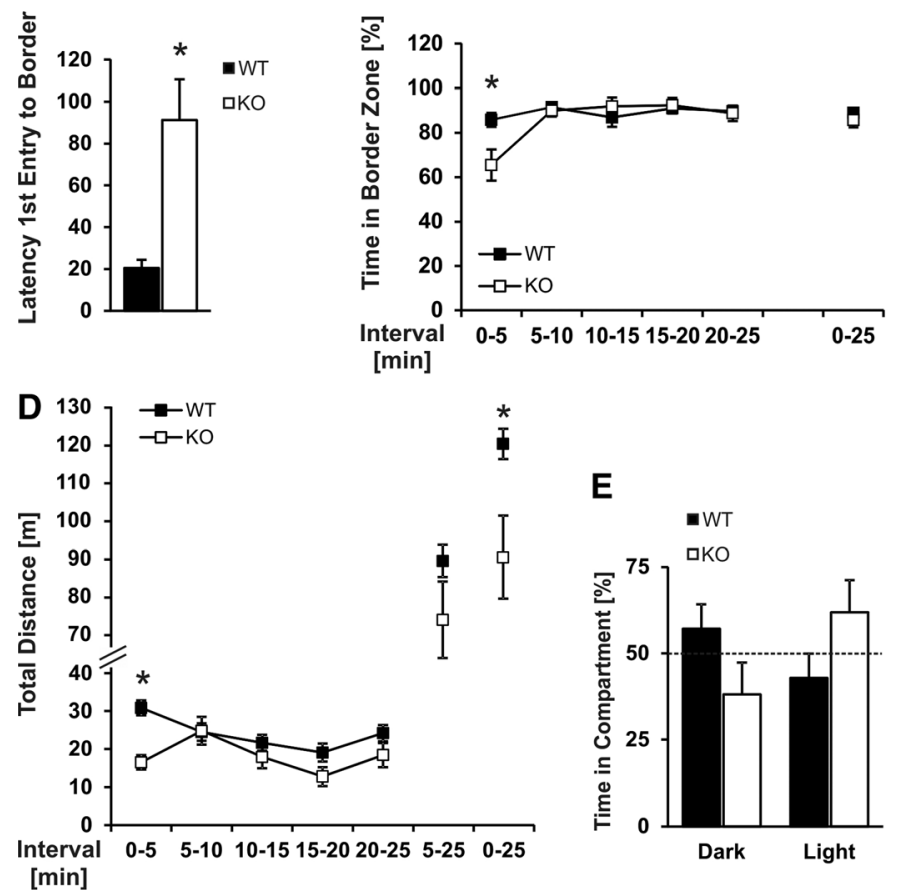

E

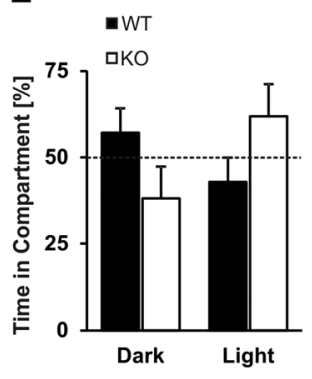

Figure 3. Slack ablation leads to an altered explorative behavior, decreased locomotor activity, an atypic initial response in an open field test and affects dark-light transition. $(A)$ Latency to enter the virtual border zone during the open field test was significantly increased for Slack KOs, hence $(B)$ initially Slack KOs spent less time in the border zone. (C) Number of rearing events during the first 5 min of the open field test was decreased in Slack KO mice. (D) Slack KOs moved less during the 25 min open field test. The behavior of the animals was tracked for $25 \mathrm{~min}$ and data were integrated in 5 min periods as well as for the whole $25 \mathrm{~min}$ of the test. $(E)$ Time spent in the dark and light compartments during the dark-light-box test. $(F)$ Latency to enter the dark compartment is significantly increased in Slack-deficient mice. All data are shown as mean \pm SEM. $\left(^{*}\right) P<0.05$, indicating significant difference between WT and Slack KO mice (open field test: $n=10$; dark-light-box test: $n=12-13$ ).

within the Slack KO group. Interestingly, Slack-deficient mice and WT animals entered the open arms with the same frequency (Supplemental Fig. 3B), whereas closed arms entries were significantly reduced in the Slack KOs. Closed arm entries are often considered as a measure of general activity and in this respect Slack KOs also traveled less distance (Supplemental Fig. 3C) and exhibited an increase in their resting behavior (Supplemental Fig. 3D) during the test period. Our subsequent analysis of the trajectories for individual mice uncovered considerable differences in the explorative behavior between the two genotypes. As shown in representative tracks (Supplemental Fig. 3I, upper part) most of the WT mice used a more or less systematic and uniform strategy to explore the maze, thereby entering each of the four arms at least once (Supplemental Fig. 3E), but with a clear preference for the protected arms (Supplemental Fig. 3A). Trajectories of Slack-deficient mice, however, appeared rather different (Supplemental Fig. 3I, lower part) because a systematic approach to explore the maze does not become apparent in the mutants and their choice of the preferred arm also seems to occur more or less by chance. For example, 3 (out of 13) Slack-deficient mice spent all of their time on the open arms and did not at all enter any of the closed arms during the whole test period (Supplemental Fig. 3I, lower part), whereas with only one exception all WT animals visited all arms (Supplemental Fig. 3E,F). Accordingly, we find that the number of animals actually visiting all four arms was significantly reduced in the Slack KO group (Supplemental Fig. 3E,F).

In conclusion, results from the open field, the light-darkbox and the elevated-plus-maze tests point to altered anxiety-like
C

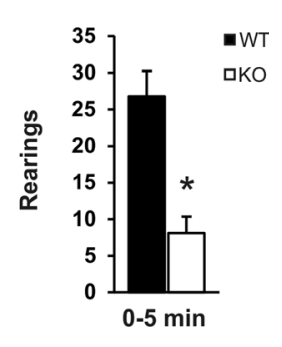

$\mathbf{F}$

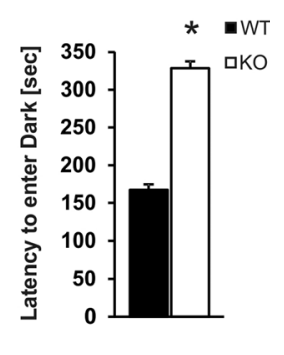

behaviors resulting from Slack ablation. High Slack expression in the amygdala (Supplemental Fig. 3G,H), a brain region that is an important part of neuronal circuits regulating anxiety and fear-related behaviors (Adhikari 2014) further supports our hypothesis of a role for Slack channels in setting a basal level of anxiety. However, all tests performed herein also depend on a normal explorative activity and we find an extremely altered explorative behavior as well as a diminished general activity in our Slack mutants.

\section{Normal spatial working memory in Slack-deficient mice}

Our analysis of Slack expression in the brain revealed the presence of this channel in layers of the hippocampus important for spatial learning and memory. Moreover, recent studies have found direct protein-protein interactions between Slack and FMRP, a protein that, when missing or mutated, causes intellectual disabilities in humans and behavioral phenotypes in mice (Brown et al. 2010; Zhang et al. 2012). We therefore tested whether Slack deficiency per se affects learning capabilities. Because Slackdeficient and WT mice performed equally in a visible platform task (Supplemental Fig. 4D), we used the hidden platform test in the Morris water maze (MWM) to address different aspects of spatial learning processes (Vorhees and Williams 2006). First, we subjected Slack KO and WT animals to a matching-to-sample version of the MWM. The matching-to-sample test serves as a working memory test because the platform position as well as the starting position is changed every day. Therefore, the animals are not able to transfer learned information about the platform position from one day to another. On each test day, they have to find the platform by chance in the first trial (matching trial). During the second trial (sample trial), they can rely on the previously memorized platform position stored in the short-term memory. Slack KO and WT mice showed decreased escape latencies during the second trial (matching trial) compared with the first trial (sample trial), indicating normal working memory capabilities of Slack mutants (Fig. 4A,B). Furthermore, time savings between trials were measured by subtracting latencies of the first and the second trial, but no significant difference between genotypes throughout the whole test phase could be observed (Fig. 4C). Since the matching-to-sample task is not easy to learn for mice, obtained latency values vary considerably especially during the first trial when the mice have to find the platform by accident. Therefore, data from three consecutive days were averaged as described earlier (Williams et al. 2003). Notably, when escape latencies and time savings were averaged over the whole test period, there was a tendency for increased escape latencies of the Slack KOs during the first trial that reached significance at the second trial in comparison to WT animals; however, time savings of Slack KOs and WT were identical (Fig. 4D). Given that identical time savings between first and second trial in the matching-to-sample test are indicative of normal working memory, these findings imply that Slack is not critical for 
A
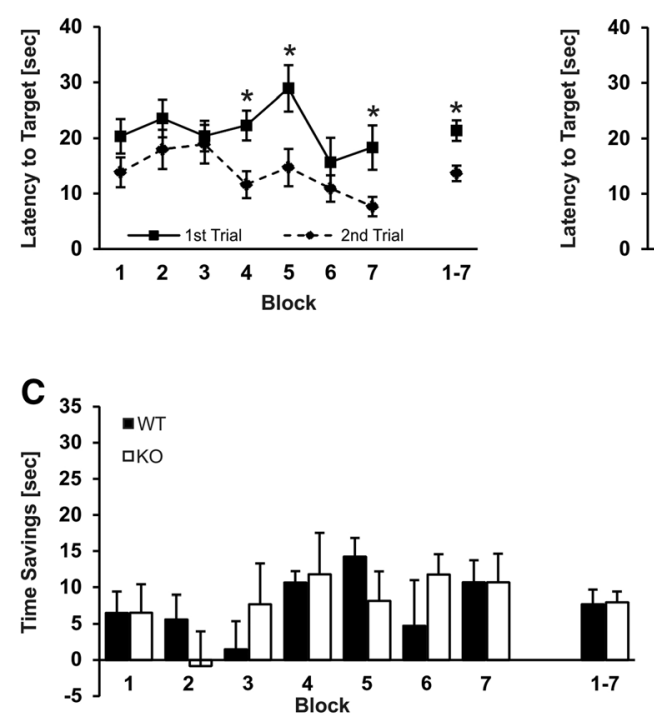

B
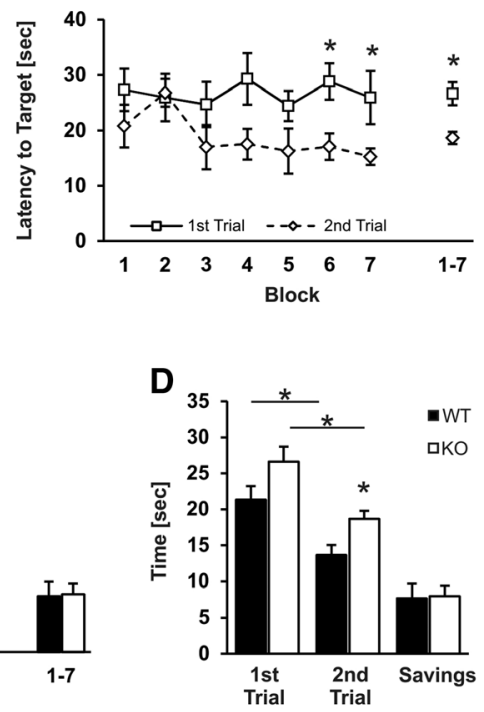

Figure 4. Slack deficiency does not affect working memory capabilities in a matching-to-sample version of the Morris water maze. Nine WT mice $(A)$ and eight Slack KOs $(B)$ were subjected to a matching-to-sample version of the Morris Water maze. Both genotypes reached the hidden platform earlier during the second trial (matching trial) as compared with the first trial (sample trial). Each data point represents average latencies of a $3 \mathrm{~d}$ block with one sample and one matching trial per day and a daily changing platform position. $\left(^{*}\right) P<0.05$, comparison first trial with second trial. (C) Time savings of WT and Slack KO mice were identical across the whole test duration. $(D)$ Mean latencies to reach the platform during the first and second trial and time savings averaged over the whole test duration (21 d). Mean latencies to target during the first trial and the second trial were increased for Slack KOs while time savings are not different compared with WT mice. $\left(^{*}\right) P<0.05$, comparison as indicated. All data are shown as mean \pm SEM. For illustrative purposes, the data were grouped in 3-d blocks.

normal working memory processes. The fact that Slack KOs did not reach the escape latencies of WT mice either during the first or during the second trial may be attributed to enhanced floating behaviors of the Slack KOs (data not shown) and may thus underscore our earlier assumption of a motivation phenotype (Figs. 2G, 3A) associated with Slack ablation in mice.

\section{Spatial acquisition learning in the Morris water maze is mildly impaired by Slack ablation}

Since Slack KOs showed normal working memory, we next performed a hidden platform test addressing spatial reference memory. During a spatial acquisition phase, mice were trained on five consecutive days with a set of four trials a day to find a hidden platform located in the middle of the southwest (SW) quadrant of the pool. During the acquisition phase, Slack KO and WT animals showed similar escape latencies (Fig. 5A). In the probe trial, Slack KOs and WT reached the former platform position with similar latencies (WT: $10.90 \mathrm{sec} \pm 2.00$; KO: $13.21 \mathrm{sec} \pm 2.31$; $P=0.452$ ) (Fig. 5A) and although both genotypes showed a preference for the former platform quadrant (SW) (Fig. 5C) Slack KO mice crossed the original platform position less frequently than WT mice $(1.85 \pm 0.27$ and $3.23 \pm 0.45$, respectively; $P=0.015)$ (Fig. 5B). These findings implicate that Slack $\mathrm{KO}$ mice remember the approximate former location of the platform, but they are unable to locate the position precisely. Importantly, mean speed, resting time, zone transition numbers, and mean directionalities were identical between genotypes during the whole acquisition phase (data not shown) and probe trial 1 (Fig. 5D). Additionally, path lengths to reach the platform correlate well with latencies across the whole test and are shown in Supplemental Figure 4C.
Slack-deficient mice show impaired spatial reversal learning in the Morris water maze

After the acquisition phase of the MWM a spatial reversal phase was performed with the platform located in the opposite quadrant of the pool (NE). As expected, during the first trial of spatial reversal, animals of both genotypes needed longer to locate the new platform position as compared with the last trial of the acquisition phase (Supplemental Fig. 4A), confirming usage of spatial orientation strategies to locate the platform. Interestingly, we observed a clear learning effect in the WT group across the first reversal day, whereas Slack KOs did not improve their performances over the first four reversal learning trials (Supplemental Fig. 4A,B). Differences between groups reached statistical significance on Day 1 for trial 3 (WT: $14.63 \mathrm{sec} \pm 3.79$; KO: $33.79 \mathrm{sec} \pm 6.44 ; P=0.019)$ and 4 (WT: $13.96 \mathrm{sec} \pm 4.96 ; \mathrm{KO}: 31.08 \mathrm{sec} \pm 6.51$; $P=0.049$ ). This was consistent with higher average escape latencies during the first reversal day in Slack KOs (WT: $18.43 \mathrm{sec} \pm 2.51 ; \mathrm{KO}: 32.15 \mathrm{sec} \pm 2.42$; $P=0.013$ ) (Fig. 5A). Escape latencies of Slack KOs started to decrease only at the second day of reversal learning, at the time that WT animals had almost reached their maximal performance level (Supplemental Fig. 4A,B). During the next days of spatial reversal training the initial differences between groups disappeared and both genotypes performed equally during probe trial 2 (Fig. 5BD). During the reversal learning, especially during early phases of spatial reversal, already learned facts such as the former platform position, become useless and have to be substituted by new information. Hence, the results from the reversal learning in the MWM may point to an important role for hippocampal Slack channels in cognitive flexibility.

\section{Slack KO mice use unconventional search strategies in the modified Barnes maze}

Swimming is not a typical behavior of mice. During the MWM test, water acts as an aversive stimulus that reinforces the mice to enter the platform, hence MWM tasks are stressful for mice (Harrison et al. 2009) and stress has been shown to affect learning and memory performance (Francis et al. 1995; Roozendaal et al. 2009; Yu et al. 2012). To evaluate escape and search strategies (Harrison et al. 2006) in the absence of an aversive stimulus we used a circular Barnes maze, which was modified to test for spatial learning capabilities in mice (Koopmans et al. 2003). Taking into account our results from the open field test (Supplemental Fig. 2), we compared the total distances the animals traveled until they found the target, because this parameter is independent of mean velocity and overall resting time.

As previously observed in the open field test (Fig. 3A,B), at the beginning of the Barnes maze test the latency of first entrance to the border zone was significantly increased in Slack KO in comparison to WT animals (WT: $6.8 \mathrm{sec} \pm 7.79$; KO: $24.6 \mathrm{sec} \pm 7.79 ; P=$ 0.046) (data not shown). Importantly, in the first trial only one out of seven Slack KOs successfully entered the escape hole while 

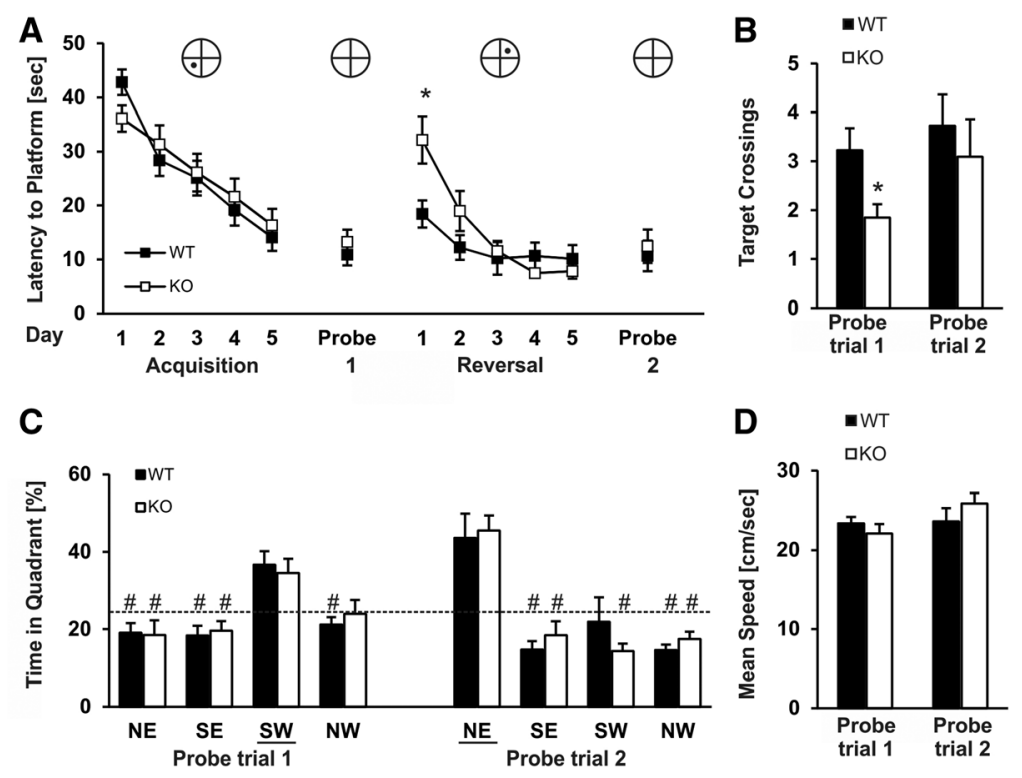

Figure 5. Slack-deficient mice show normal reference memory but delayed reversal learning in the Morris water maze. (A) Mean latencies to reach the hidden platform or original platform position during the training phases and probe trials, respectively. During the first reversal training day Slack $\mathrm{KO}$ reached the platform with an increased latency as compared with WT mice. Each individual data point represents the averaged latency of four daily trials. $\left(^{*}\right) P<0.05$, indicating significant difference between WT and Slack KO mice. (B) Mean number of crossings over the previous platform position during the acquisition probe trial (1) and the reversal probe trial (2), conducted on Day 6 and 12, respectively. Slack KOs crossed the original platform position less frequently during probe trial 1 . This difference was not apparent during probe trial $2 .\left(^{*}\right) P<0.05$, indicating significant difference between WT and Slack KOs. (C) Both, WT and Slack-deficient mice showed a clear platform quadrant preference during both probe trials. Note, during the acquisition training phase the platform was located in the SW quadrant of the maze and during the reversal training phase in the opposite quadrant (NE). (\#) $P<$ 0.05 , comparison target quadrant with nontarget quadrant. $(D)$ Both genotypes moved with a similar velocity during the probe trials. $n=20-22$ WT and Slack KO were subjected to the acquisition phase of the test, $n=11$ animals per genotype conducted the additional reversal learning phase. All data are presented as mean \pm SEM.

only three out of eight WT mice failed to reach the target. Throughout the $4 \mathrm{~d}$ of spatial acquisition, the path length of both Slack KO and WT mice improved, with a tendency for WT mice to travel greater distances until target hole entry, a difference that reached statistical significance only on the third day of the test (Fig. 6A). Both genotypes showed no clear preference for the target quadrant in comparison with the nontarget quadrants throughout the acquisition phase (Fig. 6C left). Additionally, neither the number of total errors (Fig. 6B) nor primary errors differed between the genotypes (data not shown) although the total number decreased from trial 2-4 in both genotypes (Fig. 6B). During the first probe trial after the acquisition training phase both Slack KO and WT mice exhibited a tendency for a target quadrant preference that was not different between genotypes (Fig. 6C right); however, the number of total errors was greatly increased in the Slack mutants (WT: $11.6 \pm 2.46$; KO: $24.3 \pm 4.31 ; P=$ 0.020) (Fig. 6B). Finally, in the reversal learning probe trial a tendency for an increased number of total errors in Slack KOs became apparent, but this did not reach statistical significance (Fig. 6B).

Most errors made by the WT animals during probe trial 1 were indeed primary errors because, in nearly all cases, they stopped visiting any additional holes after having encountered the previous target hole. In contrast, Slack KOs kept on exploring the maze after they had visited the former target hole. The day after the probe trial, we started a spatial reversal test with the escape hole moved to another location of the maze. Throughout the reversal training phase, we observed a clear tendency for WT mice to travel greater total distances as compared with Slack KOs (Fig. that promote reversal of memory.

\section{Discussion}

In this study, we analyzed a recently generated mouse model with a genetic ablation of the sodium-activated potassium channel Slack to examine whether endogenous Slack channels play a role in behavioral processes such as cognition, locomotion, and initial adaptation to novel situations. We found that Slack-deficient mice exhibit several behavioral phenotypes, including decreased overall locomotor activity in an open field (Fig. 3), atypic initial responses to novelty, and initial defects during reversal learning tasks (Fig. 5, 6). Interestingly, lack of Slack did not affect working memory or general reference memory as well as motor coordination on an elevated beam.

Studies of excised inside-out patches from Slack-transfected cells have found relatively high sodium concentrations required for a half-maximal activation of these channels (Bhattacharjee et al. 2003; Yuan et al. 2003). High $\mathrm{EC}_{50}$ values could point to a selective role for Slack channels in pathophysiological conditions, such as ischemia (Yuan et al. 2003; Ruffin et al. 2008) or epilepsy (Aminkeng 2012; Igelström 2012), when sodium homeostasis of the cells is disturbed. Nevertheless, it is apparent from cellattached patch recordings of both native neurons and cells expressing Slack heterologously that these channels are already open at resting levels of internal sodium (Haimann et al. 1992; Yang et al. 2007; Kim et al. 2014). Rundown of sensitivity to 

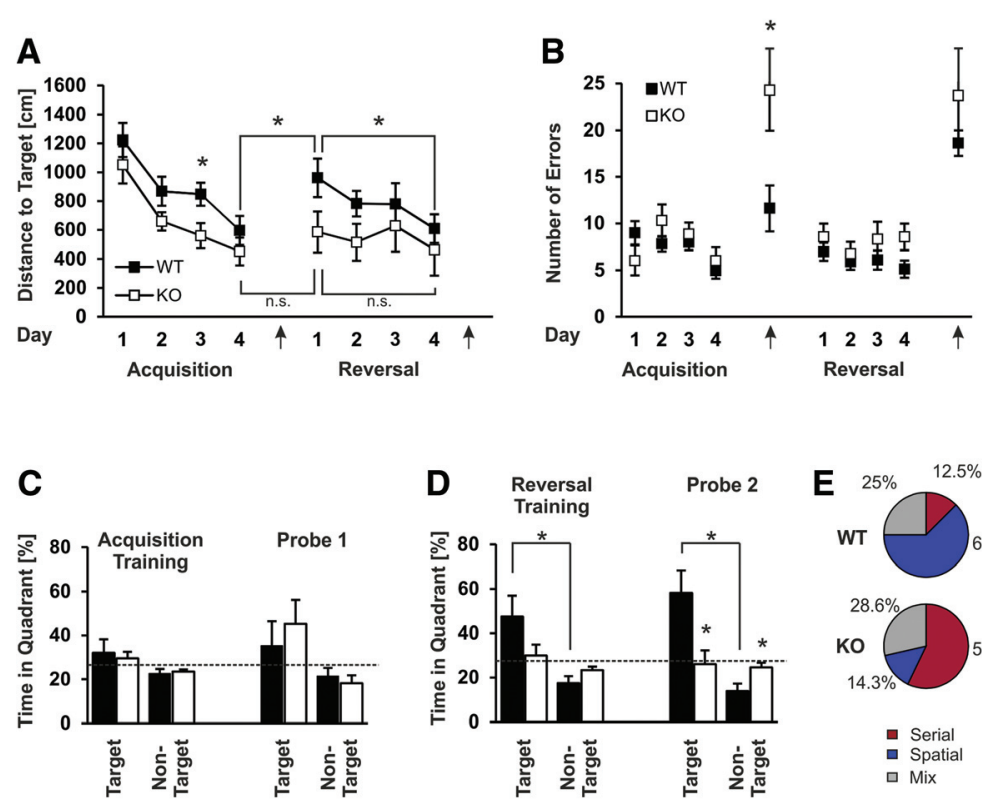

Figure 6. Slack KO and WT mice use different search/escape strategies during the reversal phase in a modified Barnes maze task. (A) Mean distances traveled by WT and Slack KO mice until entering the target hole during the acquisition and reversal training phases of the test. On repositioning of the target hole location at Day 6 only the WT group performed worse as expected. Moreover, WT mice but not Slack KOs improved across the $4 \mathrm{~d}$ of reversal training. Arrows indicate the time points of the 1 st and 2 nd probe trials. (B) Mean numbers of total errors during the different phases of the test. Arrows indicate time points of the 1 st and 2 nd probe trials. (C) Percentage of time spent in the target quadrant versus the averaged nontarget quadrants during the acquisition training phase (average of all four training days) and during probe trial 1. (D) Percentage of time spent in the target quadrant versus the averaged nontarget quadrants during the reversal training phase (average of all four training days) and during probe trial 2. (E) During probe trial 2 (conducted at Day 10), the search strategy of each individual mouse was categorized either as serial (red), spatial (blue), or mixed (gray). Data represent the percentage of animals that used the different search strategies. $\left(^{*}\right)$ $P<0.05$ and n.s. $(P \geq 0.05)$ indicate significant or nonsignificant differences between WT $(n=8)$ and Slack KO $(n=7)$ mice, respectively, or as indicated. All data are presented as mean \pm SEM.

sodium following excision of patches is likely to be due to loss of cytoplasmic factors such as $\mathrm{NAD}^{+}$(Tamsett et al. 2009). Our present studies at the whole animal level show for the first time in a physiological setting that Slack-channel activity is required for complex neuronal processes that underlie higher brain functions.

Expression patterns of Slack in the brain have been investigated in several previous studies (Bhattacharjee et al. 2002; Santi et al. 2006; Brown et al. 2008, 2010). Differences in neuronal Slack expression patterns found using different techniques such as in situ hybridization or immunocytochemistry with different antibodies may result from the presence of different Slack isoforms, which may vary in their cellular distribution and among species (Brown et al. 2008) and none of the previous studies included a Slack null control to ensure specificity of the anti-Slack antibodies used. To eliminate these uncertainties we used a previously established anti-Slack-B antibody (Bhattacharjee et al. 2002) and a novel C-terminal anti-Slack antibody that detects all known Slack isoforms. The specificity of both antibodies was demonstrated by absence of specific staining in the Slack knockout tissue (Fig. 1D,F; Supplemental Fig. 1B,D). In contrast to previous data (Brown et al. 2008), we found similar staining patterns for both antibodies, suggesting that most Slack channels expressed in the hippocampus and cerebellum are either Slack-B homomeric channels or Slack-B/Slick heteromers. Consistent with other studies (Bhattacharjee et al. 2002), we detected neither Slack-B nor total Slack protein in the cerebellar Purkinje cell layer but found high Slack-B abundance in the cerebellar granular layer (Fig. 1C). This was corroborated by our results with the C-terminal antibody,

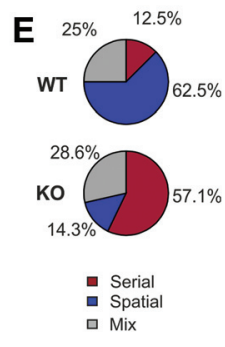

i.e., the same regions were stained, and with this antibody additional immunoreactivity in the cerebellar molecular layer containing the parallel fibers and Purkinje cell dendrites was observed (Supplemental Fig. 1A), suggesting that Slack-A is the major isoform in this brain region.

Despite high Slack expression levels in the cerebellum, Slack deficiency does not affect general motor performance as assessed by foot print analysis and an elevated-beam walk test (Fig. 2). Because normal motor functions are basic requirements for experimental protocols that test learning abilities in mice, the lack of defects in motor coordination in Slack-deficient mice is an important prerequisite for the correct execution and interpretation of subsequent behavioral experiments performed within this study.

A typical behavior that we observed in Slack-deficient mice was an initial hesitation when the animals were exposed to unfamiliar tasks or environments. This is reflected by a delay in time Slack KOs needed to cross the first elevated beam on the test day (Fig. 2G) and increased latencies to enter the border area during the open field (Fig. 3A) or the modified Barnes maze test on the first training trial and to enter the dark compartment during the dark-lightbox test (Fig. 3F). This abnormal behavior was apparent in response to a new experimental setup and usually disappeared as the animals were allowed to familiarize to the situation. In consequence, Slack KOs spent significantly more time in the center than their WT counterparts during the first $5 \mathrm{~min}$ interval of the open field test. These findings imply that Slack channels may also play a role in setting the threshold of baseline anxiety levels. Time spent in the center of the arena, especially during the initial phase of the test, is, however, a negatively related measure of anxiety (Choleris et al. 2001; Carola et al. 2002), on the other hand, anxious adult mice usually move less during the first $5 \mathrm{~min}$ of the test as did the Slack KO mice (Fig. 3D). Notably, both anxiety-related measures (center time and ambulation) provide controversial results, implying decreased and increased basal anxiety levels of Slack KOs, respectively. Furthermore, other measures negatively related to emotionality, such as the defecation frequency in the open field i.e., the total number of fecal boli, were not different between the genotypes. To further clarify the role of Slack in anxiety-related behaviors, we conducted two additional tests, the dark-light-box and the elevated-plus-maze tests (Fig. 3E,F; Supplemental Fig. 3). While the results of the dark-light-box test further support the idea of decreased anxiety levels in Slack KOs as they showed an increased latency to enter the dark compartment, the most striking outcome of the elevated-plus-maze test was an altered explorative behavior of Slack KOs that may superimpose the anxiety phenotype. Since most of the tests studying unconditioned anxiety largely depend on normal explorative behavior and locomotion, it is presently difficult for us to estimate the impact of endogenous Slack channels in regulating anxiety by studying our global Slack mutant mouse model. 
Future studies on tissue-specific Slack KOs that show a normal explorative behavior but selectively lack Slack channels in brain regions involved in anxiety-related neuronal circuits (e.g., the amygdala or the prefrontal cortex) will be required to adequately address this issue (Lu et al. 2015).

While the first part of an open field test is a suitable test to assess emotional reactivity, the later phase is a good measure for general activity of mice (Gould et al. 2009). Locomotor activity of Slack-deficient mice remained lower across the whole test period because Slack mutants traveled shorter overall distances (Fig. 3D), spent more time resting and moved with a lower mean speed than their WT counterparts (Supplemental Fig. 2). These findings could be reproduced in the elevated-plus-maze, where Slack KOs also moved less and showed increased resting periods (Supplemental Fig. 3). We therefore chose the actual distance traveled until the mice reached the target hole as the primary measure of interest in the modified Barnes maze test (Fig. 6A) because this parameter is independent of resting times and differences in mean velocity of the animals. In the open field test, activity of the probands is driven by spontaneous explorative behavior of the animals, which is also affected by instinctive fear of the novel unprotected environment they are presented with (Gould et al. 2009). In the Barnes maze test, the animals require additional mental capacities because they have to solve a particular problem, namely finding the target hole with their home cage that provides an escape from the arena of the Barnes maze apparatus. Interestingly, in contrast to the findings with the open field test, mean speed between Slack KO and WT animals in the Barnes maze and Morris water maze task (Fig. 5D) was not different, although we observed increased floating behavior of Slack-deficient mice during the $21 \mathrm{~d}$ of the matching-to-sample test (Fig. 4D) and a tendency for an increased resting throughout the whole Barnes maze test (data not shown). Overall, the increase in resting/floating behavior of Slack KOs seems to be independent of different motivations, whereas the difference in mean speed between Slack KOs and WT animals only became obvious during spontaneous activity of the animals in a more or less "stress-free" setting. Additionally, the differences in explorative behaviors between Slack KO and WT mice observed in the elevated-plus-maze test did not negatively impact the results of the Barnes maze test since performances of the Slack KOs were not impaired during the acquisition phase that would be most likely affected by a decreased explorative drive.

A key finding of this study is that Slack ablation at the whole animal level causes distinct learning deficits. While working memory and acquisition reference memory were not affected by the channel ablation (Figs. 4, 5), a learning defect emerged during the reversal learning phases of both experimental paradigms (water and circular maze). The cellular mechanisms affected by the lack of Slack during reversal learning and cognitive flexibility are far from understood. In general, impaired reversal learning has been found in mice with defective long-term depression (LTD) (Nicholls et al. 2008; Kim et al. 2011; Mills et al. 2014), whereas other studies point to an predominant role of depotentiation of previously strengthened synapses (after long-term potentiation (LTP) induction) for normal spatial reversal learning and memory extinction (Serrano et al. 2008; Zhang et al. 2011; Zhang and Wang 2013). Moreover, there is also some evidence that the balance between LTP and synaptic depotentiation is essential for behavioral flexibility (Errico et al. 2008; Zhang and Wang 2013). How Slack channels are implicated in these molecular processes and whether Slack deficiency leads to defects in bidirectional synaptic plasticity needs to be established by further studies. Slack channels have previously been found to play an important role in regulating the accuracy of timing of action potential generation in response to incoming synaptic stimuli in the medial nucleus of the trapezoid body (Yang et al. 2007). Based on these previous findings, we speculate that Slack may be an important factor within the complex neuronal circuits of the hippocampus regulating correct processing of incoming information. Absence of Slack could lead to errors of timing that result in the mild learning deficits of Slack-deficient mice observed in this study. Moreover, Slack channels contain a PDZ binding motif and interact with PSD95 (Uchino et al. 2003), which is implicated in clustering of ion channels, ionotropic receptors and other scaffolding proteins in synaptic regions (Harris and Lim 2001). These properties point to a postsynaptic localization of Slack channels and it has been shown that Slack interacts physically and functionally with AMPA receptors in the spinal cord where it modulates synaptic transmission by providing a negative feedback affecting excitatory postsynaptic currents following AMPA receptor activation (Nanou and El Manira 2007; Nanou et al. 2008). Because the importance of AMPA receptors for synaptic plasticity in the hippocampus is well established (Banke et al. 2000; Collingridge et al. 2004; Malenka and Bear 2004), a putative AMPA/Slack interactions in the postsynapse may affect potentiation and thereby spatial learning and memory processes.

It has recently been suggested that Slack could act as an activity sensor that provides a link between neuronal activity and activity-dependent protein synthesis, possibly via retrograde interaction of Slack and FMRP (Zhang et al. 2012). Activity-dependent protein synthesis is important for synaptic plasticity and cognition (Krug et al. 1984; Katz and Shatz 1996; Sakata et al. 2013). Furthermore, changes in gene expression appear to be essential for memory extinction, as inhibition of gene transcription and protein synthesis interfere with memory extinction in an conditioned avoidance paradigm (Vianna et al. 2003). Thus loss of Slack channels could lead to defective activity-dependent protein synthesis, affecting molecular processes that are crucial for memory extinction and relearning.

The question of whether diminished Slack activity is responsible for some aspects of the phenotype of FXS patients and Fmr1 knockout mice (Fmr1 KOs) cannot fully be answered by this study. However, our study provides some evidence that Slack channel activity may be important in FXS. Brown et al. (2010) have already reported decreased Slack channel activity in Fmr1-deficient mice and we have demonstrated that Slack ablation leads to several behavioral deficits that are in part consistent with the defects of Fmr1 KOs. A detailed comparison of the phenotype of our Slack-deficient mice with the published phenotype of Fmr1 KO mice reveals overlapping phenotypes as well as some discrepancies. There exist, however, some similar discrepancies in different studies of the behavioral phenotype of Fmr1 knockout mice (Paradee et al. 1999; Yan et al. 2004). For example, in one study general motor coordination of Fmr1-deficient mice has been found to be normal in regard to footprint patterns and performance in an elevated-beam assay (Roy et al. 2011), whereas another study reported impaired motor skill learning (Padmashri et al. 2013). Our study revealed normal motor functions on an elevated beam and normal gait of Slack-deficient mice but we did not test motor skill learning abilities in this study. In contrast to the hyperactivity of Fmr1 KO mice reported in several publications (The Dutch-Belgian Fragile X Consortium et al. 1994; Peier et al. 2000; Moy et al. 2009; Pietropaolo et al. 2011), Slack KOs exhibit lower spontaneous locomotor activity in the open field test. Nevertheless, hyperactivity of Fmr1 KO mice has not been reported consistently and appears to be strongly influenced by differences in genetic backgrounds. Most studies that used Fmr1-deficient mice on a C57BL/ 6 background did not report altered locomotor activity (Nielsen et al. 2002; Yan et al. 2004; Moy et al. 2009; Baker et al. 2010; Pietropaolo et al. 2011; Udagawa et al. 2013) and our 
Slack mutants were also backcrossed to the C57BL/ 6 background. Moreover, several studies have reported that Fmr1 KOs show an increased center time in the open field test (Peier et al. 2000; Yan et al. 2004; Baker et al. 2010; Udagawa et al. 2013), which is again in line with our findings in the Slack mutant mouse line. Others, however, have not readily reproduced such differences between Fmr1 KO and WT mice (Roy et al. 2011).

The greatest similarities between the behavioral phenotype of Slack KOs and Fmr1 KOs are found in the learning and memory phenotype of both mutant mice strains. Many (The DutchBelgian Fragile X Consortium et al. 1994; D'Hooge et al. 1997; Dobkin et al. 2000; Van Dam et al. 2000; Baker et al. 2010) but not all (Paradee et al. 1999; Peier et al. 2000; Yan et al. 2004) studies describe mildly impaired strain dependent learning abilities for Fmr1 KOs in the Morris water maze. We have shown that Slack $\mathrm{KO}$ and WT mice perform similarly during the acquisition training phase of the Morris water maze test (Fig. 5A). After changing the platform position, Slack KOs exhibit initial difficulties in locating the hidden platform, but with adequate training reached the performance level of WT mice. Notably, such initial deficits during reversal learning have also been reported in several studies of the learning abilities of Fmr1-deficient mice (The Dutch-Belgian Fragile X Consortium et al. 1994; D'Hooge et al. 1997; Van Dam et al. 2000). In addition, we found striking differences between Slack KO and WT animals during the reversal learning phase of a modulated Barnes maze test, where Slack-deficient mice used different escape strategies from those of their WT counterparts (Fig. 6E; Supplemental Fig. 5) and did not at all exhibit a target quadrant preference (Fig. 6D). A very similar result has been found for Fmr1-deficient mice (Yan et al. 2004). Target quadrant preference was absent during a Barnes maze probe trial at the end of the reversal training phase, and the authors noted a difference in search strategies between Fmr1 mutants and WT mice (Yan et al. 2004).

In conclusion, we have provided evidence for a role for endogenous Slack channels in higher brain functions, i.e., learning and memory, cognitive flexibility, locomotoric and the ability to initially respond to novel situations and environments. Because some of the behavioral phenotypes of Fmr1-deficient mice were reproduced in the Slack mutant mouse line, our findings also further support the recent view of a common FMRP/ Slack pathway that underlies distinct cognitive capabilities in mice and that is perturbed in human FXS patients.

\section{Materials and Methods}

\section{Animals and animal care}

Slack-deficient mice were generated by a targeted ablation of Kcnt1 in murine embryonic stem cells in combination with a common Cre/loxP-system as described previously (Lu et al. 2015). Experimental mice were back crossed for at least six generations to a C57BL/6N background before they were used for expression analysis or behavioral experiments. Behavioral experiments were performed in 2- to 6-mo old age-matched male mice obtained by mating heterozygous $\left(\mathrm{Slack}^{+}{ }^{-}\right.$) parental animals. Most of the animals used were littermates. Animals were maintained on a 12/12 $\mathrm{h}$ light-dark cycle with access to food and water ad libitum. All experiments were conducted during the light phase between 8:00 a.m. and 6:00 p.m. Mice were allowed to acclimatize to the experimental room for 1-2 d after being transferred from breeding colony. All experimental procedures were conducted in accordance with the animal protection laws in Germany and were approved by the local Ethics Committee for Animal Research (Regierungspräsidium Tübingen). For all experiments that included nonlitter-matched animals separate subgroup analyses were performed. These analyses revealed the same results for the littermate-subgroups and the total group of mice, which includes the nonlittermates.

\section{Production and purification of rabbit anti-Slack antiserum and antibody}

A recombinant fusion protein comprising of a N-terminal polyhistidine tag and amino acids (1012-1238) of the murine slo2.2 isoform 1 (Slack-B) (Accession No. NP_780671 XP_622105) (representing the last 227 amino acids of the Slack C-terminus) was expressed in E. coli BL21(DE3)pLysS (Invitrogen). After cells were harvested and lysed, inclusion bodies containing the recombinant protein were washed subsequently in solutions with increasing concentrations of Triton-X-100 and guanidine- $\mathrm{HCl}$ before solubilization in buffer containing $6 \mathrm{M}$ guanidine- $\mathrm{HCl}$ as described earlier (Sausbier et al. 2006). The crude protein extract was further purified under denaturing conditions using Ni-NTA superflow (Qiagen) according to manufacturer's instructions. Subsequently, the pure fusion protein was concentrated using a Vivaspin-20 concentrator (Sartorius). The polyclonal anti-Slack antiserum was generated in rabbits. For immunhistochemical approaches the obtained antiserum was purified at PVDF membranes $\left(4^{\circ} \mathrm{C}\right.$ overnight incubation) spotted with the recombinant fusion protein as described earlier (Sausbier et al. 2006). The PVDF membranes were washed twice with $10 \mathrm{mM} \mathrm{K}_{3} \mathrm{PO}_{4}(\mathrm{pH}$ 6.8) before elution of the antibody with $0.1 \mathrm{M}$ glycine $(\mathrm{pH} 2.5)$. The $\mathrm{pH}$ of the eluates was adjusted to $\mathrm{pH} 7.4$ with $1 \mathrm{M} \mathrm{K}_{3} \mathrm{PO}_{4}(\mathrm{pH} 8.0)$, and eluates were dialyzed at $4^{\circ} \mathrm{C}$ overnight against storage buffer $(0.5 \mathrm{M}$ $\mathrm{NaCl}, 0.1 \mathrm{M} \mathrm{K}_{3} \mathrm{PO}_{4}, 2 \mathrm{mM}$ EDTA, $2 \mathrm{mM}$ benzamidine-HCl; $\mathrm{pH}$ 7.0) and concentrated using a Vivaspin-20 concentrator.

\section{Quantitative real-time ( $q R T$-) PCR}

Brains were rapidly dissected, cerebellum and hippocampi were isolated and either snap frozen in liquid nitrogen and stored at $-80^{\circ} \mathrm{C}$ until further processed or homogenized in PeqGOLD RNApure (Peqlab) without prior freezing. Total RNA was extracted under RNase-free conditions according to the manufacturer's instructions. In order to minimize genomic DNA extracted RNA samples were DNAse treated for $30 \mathrm{~min}$ and quantified with a NanoPhotometer Pearl (Implen). Five hundred nanograms RNA were used for first strand cDNA synthesis according to manufacturer's instruction using iScript cDNA Synthesis Kit (Bio-Rad Laboratories). Real-time RT-PCR was performed on a CFD-3200 DNA Engine Opticon Real-Time PCR Cycler (MJ Research) with iQ SYBR Green Supermix (Bio-Rad Laboratories) according to the manufacturer's instructions. PCR reactions were performed in triplicate by incubating at $98^{\circ} \mathrm{C}$ for $1 \mathrm{~min}$, followed by 40 cycles of $5 \mathrm{sec}$ at $98^{\circ} \mathrm{C}$ and $15 \mathrm{sec}$ at $58^{\circ} \mathrm{C}$. Water controls and (-)RT samples (where reverse transcriptase was omitted during the first strand synthesis) were included to ensure specificity of the primer pairs. Relative expression of target gene levels was determined using the comparative $2^{-\Delta \Delta \mathrm{Ct}}$ method, with Ct indicating the cycle number at which the signal of the PCR product crosses an arbitrary threshold set within the exponential phase of the PCR. Expression levels were normalized to HPRT. Primers specific to target RNAs were selected using Primer3 software. Primer sequences were: Slack forward 5'-CTGCTGTGCCTGGTCTTCA-3', Slack reverse 5'-AAGGAGGTCAGCAGGTTCAA-3'; Slick forward 5'-CG CTGCGAAGTGGATAGAAC-3', Slick reverse 5'-TGGGGCAAAA TCTTTCACAG-3' HPRT forward 5'-CATTATGCCGAGGATTTG GA-3', HPRT reverse 5'-CCTTCATGACATCTCGAGCA-3' .

\section{Western blots}

Brains were rapidly dissected, cerebellum and hippocampi were isolated and homogenized in buffer containing $100 \mathrm{mM}$ Tris$\mathrm{HCl}$ and $1 \mathrm{mM} \mathrm{MgCl}_{2}, \mathrm{pH} 8.0$, supplemented with a protease inhibitor mixture (Mini Tablets; Roche). Following freezing at $-80^{\circ} \mathrm{C}$ for $30 \mathrm{~min}$, samples were homogenized with a glass Teflon potter. After adding a fivefold volume of sucrose buffer (250 mM sucrose, $10 \mathrm{mM}$ Tris- $\mathrm{HCl}, \mathrm{pH} 7.4$, combined with protease inhibitor mixture), the samples were mixed and centrifuged at $1000 \mathrm{~g}$ for $20 \mathrm{~min}$. The supernatant was collected and centrifuged at $20,000 \mathrm{~g}$ for $20 \mathrm{~min}$, and the resulting pellets were suspended in sucrose buffer. Extracted proteins were separated by SDS-PAGE and blotted onto a PVDF membrane. After blocking of nonspecific 
binding sites with 5\% low-fat milk in TBST (Tris-buffered saline containing Tween 20), membranes were incubated overnight at $4^{\circ} \mathrm{C}$ with rabbit anti-Slack serum or mouse anti- $\alpha$-tubulin (1:1000; Cell Signaling Technology) dissolved in TBST containing $5 \%$ bovine serum albumin (BSA). After incubation with Cy3 or Cy5 labeled secondary antibodies (GE Healthcare) for $1 \mathrm{~h}$ at room temperature, proteins were detected using an Ettan DIGE system (GE Healthcare). Pre-adsorption of the crude anti-Slack Serum at Slack KO brain homogenate increases specifity as shown in Supplemental Figure 1F. The Slack KO brain is rapidly dissected, washed in ice-cold PBS, and homogenized in $1 \mathrm{~mL}$ PBS containing $0.4 \%$ Triton $\mathrm{X}$ and protease inhibitor mixture. Fifty microliters of the anti-Slack serum is added to the homogenate and incubated for $2 \mathrm{~h}$ on an overhead laboratory shaker at $4^{\circ} \mathrm{C}$. To harvest the preadsorbed serum the homogenate is centrifuged at $18,000 \mathrm{~g}$ for 15 min and the supernatant is again centrifuged at 100,000g for 60 min. The supernatant is supplemented with sodium azide to a final concentration of $0.05 \%$ and used for immunoblot detection.

\section{Immunohistochemistry}

Mice were killed by $\mathrm{CO}_{2}$ and immediately perfused intracardially with $1 \%$ or $2 \%$ paraformaldehyde in PBS, $\mathrm{pH} 7.4$. Brains were dissected, post-fixed for $2 \mathrm{~h}$ and cryoprotected in $30 \%$ sucrose for at least $24 \mathrm{~h}$ at $4^{\circ} \mathrm{C}$. Tissues were frozen in tissue freezing medium (Thermo Fisher Scientific), cryostat sectioned coronally at a thickness of $10 \mu \mathrm{m}$, and stored at $-20^{\circ} \mathrm{C}$. For alkaline phosphatasebased immunohistochemistry (IHC), sections were incubated in $1 \% \mathrm{H}_{2} \mathrm{O}_{2}$ in PBS for $10 \mathrm{~min}$, blocked and permeabilized for $1 \mathrm{~h}$ in blocking solution (5\% normal goat serum, 5\% normal donkey serum, $1 \%$ BSA, $0.2 \%$ Glycine, $0.2 \%$ Lysine, and $0.3 \%$ TritonX-100 in PBS), and incubated with primary antibodies diluted in blocking solution overnight at $4^{\circ} \mathrm{C}$. The in-house generated rabbit anti-Slack (1:2000) antibody and a previously published Slack-B specific antibody (chicken anti-Slack-B (1:3000)) were used for IHC (Bhattacharjee et al. 2002). Sections were then washed in PBS and incubated with biotinylated secondary antibodies antirabbit IgG (Vector Laboratories) or anti-chicken IgY (Jackson Immuno) diluted 1:1000 in blocking solution. The VECTASTAIN ABC-AP Kit and Vector Blue AP Substrate Kit (Vector Laboratories) supplemented with levamisole solution to block endogenous alkaline phosphatase activity were used according to the manufacturer's instructions for visualization of target proteins. Images were taken using an Axiovert 200M microscope (Carl Zeiss) equipped with a color camera Axiocam MRc Rev.3. Controls were performed by omitting the primary antibodies and by parallel staining of tissues obtained from Slack KO mice.

\section{Footprint analysis}

Footprint analysis was performed as described earlier (Sausbier et al. 2004). In brief, hindpaws and forepaws of five litter-matched WT and Slack KOs were dipped in red and blue water color, respectively, before walking on a white paper covering the floor of an narrow corridor. Mice were trained on three consecutive days with three trials per day before testing. Foot print patterns were analyzed for stride width, stride length, and overlap.

\section{Beam walk test}

The ability of 10 age- and litter-matched WT and Slack KOs to traverse squared and round shaped beams of various diameters was assessed (Carter et al. 2001). Beams were elevated $50 \mathrm{~cm}$ above the floor and had a length of $100 \mathrm{~cm}$. Before testing, the mice were trained for $3 \mathrm{~d}$ with four trials per day on a squared beam with $12 \mathrm{~mm}$ diameter. On the test day, the animals were tested on three different squared beams with decreasing diameters $(28 \mathrm{~mm}, 12$ $\mathrm{mm}, 5 \mathrm{~mm})$ and three different round beams $(28 \mathrm{~mm}, 17 \mathrm{~mm}$, $11 \mathrm{~mm}$ ) with two trials on each beam. Test trials were recorded with a video recorder and data were analyzed offline by an observer unaware of the genotype of the animals. Measures of interest were the latency to cross each beam, number of hind limb foot slips, and number of falls.

\section{Open field test}

Ten mice (litter- and age-matched) of each genotype were placed in the middle of a circular open field arena $(112 \mathrm{~cm}$ diameter $)$ and left undisturbed for $25 \mathrm{~min}$ while their behavior was video recorded. Latency of first entrance to a virtual border zone (a $15 \mathrm{~cm}$ broad ring beside the wall), total distance traveled, the percentage of time spent in the border zone, resting time, and mean speed was analyzed in 5 min intervals using the Smart3.0 tracking software (Panlab). Additionally, the number of rearing movements was counted during the first $5 \mathrm{~min}$ in the open field test by an observer unaware of the genotype of the animals.

\section{Dark-light-box test}

The test-apparatus consisted of a box $45 \times 20 \times 20 \mathrm{~cm}(1 \times \mathrm{b} \times \mathrm{h})$. The light compartment compromised two thirds of the apparatus, was made of clear Plexiglas, and it was lit with $450 \mathrm{~lx}$. The other part of the apparatus was nontransparent and dark. An opening $(4 \times 5 \mathrm{~cm})$ allows the transition between the two compartments. The mice were placed in the lit compartment facing the wall and were allowed to explore the apparatus for $10 \mathrm{~min}$. Measures for anxiety levels are the time spent in each compartment and latency to enter the dark compartment for the first time.

\section{Elevated-Plus-Maze test}

The plus-shaped maze was made of white plastic and consisted of four arms (two open without walls and two enclosed by $15 \mathrm{~cm}$ high walls) each $30 \mathrm{~cm}$ long and $5 \mathrm{~cm}$ wide. The maze is elevated $40 \mathrm{~cm}$ above the floor. The mice were placed in the center area facing one of the open arms and were allowed to explore the maze for 5 min without disturbance. Test sessions were video recorded and analyzed offline using Smart3.0 tracking software (Panlab). Additionally, an observer unaware of the genotype of the animals measured the time spent in each of the four arms, counted entries in the different arms and analyzed the trajectories with regard to arm entries.

\section{Morris water maze}

The Morris water maze apparatus consisted of a circular pool filled with water, $112 \mathrm{~cm}$ in diameter (Stoelting). Water temperature was maintained at $21 \pm 1^{\circ} \mathrm{C}$. For the hidden platform tests the water level was $30 \mathrm{~cm}$, and a cylindrical escape platform, $12 \mathrm{~cm}$ in diameter and made of clear plastic, was submerged $0.5 \mathrm{~cm}$ beneath the water surface. Water was made opaque by addition of powdered milk. The maze was virtually divided by two axes (N$\mathrm{S}$ and $\mathrm{W}-\mathrm{E}$ ) into four quadrants (NE, SE, SW, NW). For the visible platform test the water level was adjusted to place the platform 1 $\mathrm{cm}$ above the water surface. Additionally, the platform was tagged with a brown cylinder and a white flag to make sure that the mice were able to localize it. The platform was positioned in the middle of each quadrant as indicated. The pool was located in a room surrounded by distinct extra-maze (distal) cues. Large, black, geometric shapes were placed on two walls near the tank, a triangle in the $\mathrm{N}$ and a circle in the $\mathrm{E}$. A dark curtain on the $\mathrm{W}$ side was used to shield any other cues available in the room. The experimenter always stood upright in the S quadrant and was wearing a white laboratory coat; hence, she/he served as an additional point of orientation for the mice. A camera, located above the water tank, was attached to a computer so that the performance of each mouse could be recorded and subsequently analyzed offline by an observer unaware of the genotype of each mouse.

\section{Visible platform test}

The visible platform test was performed with ten mice per genotype over three consecutive days with four trials a day. The start position of the mice as well as the platform position was changed in between each trial in a pseudo-randomized manner. The inter-trial-interval (ITI) was $60 \mathrm{sec}$ with $15 \mathrm{sec}$ on the platform and $45 \mathrm{sec}$ in the home cage. Latencies to reach the visible 
platform were measured and data of the four daily trials was averaged.

\section{Matching-to-sample version of the MWM}

One day before the matching-to-sample experiment the mice (11 Slack KO and WT mice) received a pretraining session to allow the mice to acclimatize to the requirements of the Morris water maze task. The pretraining experiment consisted of four $60 \mathrm{sec}$ trials for each mouse with 30 sec ITI. The start position of the mice as well as the platform position was changed in between each trial. Animals that showed thigmotaxis or extensive floating behavior during this session were excluded from the actual experiment. The working memory matching-to-sample experiment was conducted with nine WT mice and eight Slack KOs. During 21 consecutive days of the matching-to-sample version of the Morris water maze (Williams et al. 2003), the animals were given two trials each day. Both, the start and goal positions varied every day following a pseudo-randomized order but stayed the same for the two daily trials. The first trial represents a sample trial designed to allow the animal to search and memorize the platform position, the second trial served as matching trial where the animals could retrieve the previously memorized platform position. Each trial lasted a maximum of $60 \mathrm{sec}$ and the mice were gently directed to the platform if they did not reach the platform within this $60 \mathrm{sec}$ period. In between the trials, animals were allowed to sit on the platform for $30 \mathrm{sec}$. Latencies to reach the platform were measured and time savings as a measure of working memory abilities were calculated by subtracting latencies of the first and the second trial. For illustrative purposes data were presented in 3-d blocks or as average of the whole $21 \mathrm{~d}$.

\section{Spatial acquisition and reversal (MWM)}

Spatial acquisition in the MWM was performed with $22 \mathrm{WT}$ and 20 Slack KO mice, a subpopulation of 11 mice of each genotype was further tested for their reversal learning abilities. The spatial acquisition version was designed to address place or spatial learning. During five consecutive days of acquisition, mice, starting from different, pseudo-random locations around the perimeter of the tank (N, O, SO, NW) (Vorhees and Williams 2006), had to navigate directly to the hidden platform located in the SW quadrant by the use of the distal cues. Mice received four trials a day and the ITI was $15 \mathrm{sec}$. If an animal did not find the platform within $60 \mathrm{sec}$, it was gently picked up and placed on the platform for 15 sec. The day after the last acquisition training day a probe trial was performed. During the probe trial the platform was removed. Mice starting from an unknown platform position (NE) were allowed to swim in the maze for $30 \mathrm{sec}$. Subsequent to the probe trial of the spatial acquisition version, mice were tested in the spatial reversal version of the Morris water maze. The platform was relocated to the opposite quadrant of the former position (NE) and mice were given another set of four trials per day for five consecutive days. The animals were released pseudo-randomly from four different start positions (S, W, NW, SE). At the end of the reversal phase a reversal probe trial was administered $24 \mathrm{~h}$ after the last reversal training trial. Swim trajectories of the mice were analyzed using Smart3.0 tracking software (Panlab). During acquisition and reversal training we measured latencies to reach the hidden platform as well as mean speed and path length. During the probe trials we analyzed latencies and path lengths to reach the original platform position, number of crossings over the original platform position, mean velocities of the animals and percentage of time spent in each of the four pool quadrants as a measure of reference memory.

\section{Modified Barnes maze task}

We used a circular maze originally described by Koopmans et al. (2003) to assess reference and reversal learning of eight WT and seven Slack KO mice in a less stressful setup. The maze consisted of a circular arena with a diameter of $95 \mathrm{~cm}$ surrounded by a rim $(25 \mathrm{~cm}$ high). Twelve equally spaced holes $(5 \mathrm{~cm}$ in diameter,
$0.5 \mathrm{~cm}$ above the floor) connected to horizontal, L-shaped, exit tunnels were embedded in the rim. The open end of the exit tunnels faced downside with a $45^{\circ}$ angle. One exit tunnel was attached to a tunnel extension $(17.5 \mathrm{~cm} \times 5 \mathrm{~cm})$ that gave access to the home cage of the mouse. A camera placed above the maze registered the movements of the mice. The same distal cues as in the Morris water maze were used. The performance of each mouse was analyzed using Smart3.0 tracking software (Panlab).

During the acquisition phase of the test, mice had to accomplish a set of four trials per day for four consecutive days with a fixed target hole position. One trial lasted a maximum of $4 \mathrm{~min}$. Once the animal entered the escape hole, the hole was closed at the side of the entrance to avoid reentering of the mouse to the maze. ITI was $20 \mathrm{~min}$. Mice that failed to reach the escape hole within the $4 \mathrm{~min}$ were gently guided to it. The maze was cleaned with $80 \%$ ethanol between the single trials and turned by $\sim 90^{\circ}$ to avoid the animals relying on old olfactory cues to locate the target hole. A probe trial (probe 1) was conducted $24 \mathrm{~h}$ after the last acquisition trial after the removal of the home cage with escape tunnel and lasted 4 min.

Subsequently, the escape hole position was switched to another side of the maze to assess the spatial reversal learning abilities. Mice again were trained for $4 \mathrm{~d}$ receiving four trials per day. One day after the last reversal training trial a second probe trial (probe 2) was conducted.

During the training phases we measured the distance traveled until the mice entered the target hole as well as numbers of head deflections into the different holes (errors). Data of the four daily trials were averaged. The time spent in the target quadrant (target hole and adjacent holes to the left and the right) and averaged nontarget quadrants were averaged over the whole training phase. During the two probe trials, we measured numbers of primary errors (head deflections into incorrect holes before first visit to the target hole) and total errors, time spent in the target quadrant versus the averaged nontarget quadrants. Furthermore, trajectories of each mouse obtained during probe trial 2 were analyzed by an observer unaware of the genotype of the mice and the search strategy categorized as either serial, spatial, or mixed according to Harrison et al. (2006).

\section{Statistics}

Data of WT and Slack KOs were averaged and analyzed for significant differences between groups using Student's-t-tests after testing for normal distribution and equal standard deviation. Welch correction was applied when standard deviations differed significantly. To test for improvement or worsening of the performance within the WT or Slack KO group, respectively, we used paired Student's $t$-tests. A probability value of $P<0.05$ was considered as statistically significant. All data are presented as mean \pm standard error of the mean (SEM).

\section{Acknowledgments}

We thank Clement Kabagema-Bilan for excellent technical assistance.

\section{References}

Adhikari A. 2014. Distributed circuits underlying anxiety. Front Behav Neurosci 8: 112 .

Aminkeng F. 2012. KCNT1 mutations in ADNFLE and MMPSI: a new driver in the etiology and pathophysiology of early-onset epileptic syndromes. Clin Genet 83: 319-320.

Baker KB, Wray SP, Ritter R, Mason S, Lanthorn TH, Savelieva KV. 2010. Male and female Fmr1 knockout mice on C57 albino background exhibit spatial learning and memory impairments. Genes Brain Behav 9: $562-574$.

Bakker CE, Oostra BA. 2003. Understanding fragile X syndrome: insights from animal models. Cytogenet Genome Res 100: 111-123.

Banke TG, Bowie D, Lee H, Huganir RL, Schousboe A, Traynelis SF. 2000. Control of GluR1 AMPA receptor function by cAMP-dependent protein kinase. J Neurosci 20: 89-102. 
Barcia G, Fleming MR, Deligniere A, Gazula VR, Brown MR, Langouet M, Chen H, Kronengold J, Abhyankar A, Cilio R, et al. 2012. De novo gain-of-function KCNT1 channel mutations cause malignant migrating partial seizures of infancy. Nat Genet 44: 1255-1259.

Bear MF, Huber KM, Warren ST. 2004. The mGluR theory of fragile X mental retardation. Trends Neurosci 27: 370-377.

Bhattacharjee A, Kaczmarek LK. 2005. For $\mathrm{K}^{+}$channels, $\mathrm{Na}^{+}$is the new $\mathrm{Ca}^{2+}$. Trends Neurosci 28: 422-428.

Bhattacharjee A, Gan L, Kaczmarek LK. 2002. Localization of the Slack potassium channel in the rat central nervous system. J Comp Neurol 454: $241-254$.

Bhattacharjee A, Joiner WJ, Wu M, Yang Y, Sigworth FJ, Kaczmarek LK. 2003. Slick (Slo2.1), a rapidly-gating sodium-activated potassium channel inhibited by ATP. J Neurosci 23: 11681-11691.

Bhattacharjee A, von Hehn CA, Mei X, Kaczmarek LK. 2005. Localization of the $\mathrm{Na}^{+}$-activated $\mathrm{K}^{+}$channel Slick in the rat central nervous system. J Comp Neurol 484: 80-92.

Blizard DA, Takahashi A, Galsworthy MJ, Martin B, Koide T. 2007. Test standardization in behavioural neuroscience: a response to Stanford. J Psychopharmacol 21: 136-139.

Brager DH, Akhavan AR, Johnston D. 2012. Impaired dendritic expression and plasticity of h-channels in the fmr $1(-/ y)$ mouse model of fragile $X$ syndrome. Cell Rep 1: 225-233.

Brown MR, Kronengold J, Gazula VR, Spilianakis CG, Flavell RA, von Hehn CA, Bhattacharjee A, Kaczmarek LK. 2008. Amino-termini isoforms of the Slack $\mathrm{K}^{+}$channel, regulated by alternative promoters, differentially modulate rhythmic firing and adaptation. J Physiol 586: $5161-5179$

Brown MR, Kronengold J, Gazula VR, Chen Y, Strumbos JG, Sigworth FJ, Navaratnam D, Kaczmarek LK. 2010. Fragile X mental retardation protein controls gating of the sodium-activated potassium channel Slack. Nat Neurosci 13: 819-821.

Budelli G, Hage TA, Wei A, Rojas P, Ivy Jong YJ, O’Malley K, Salkoff L. 2009. $\mathrm{Na}^{+}$-activated $\mathrm{K}^{+}$channels express a large delayed outward current in neurons during normal physiology. Nat Neurosci 12: 745-750.

Carola V, D'Olimpio F, Brunamonti E, Mangia F, Renzi P. 2002. Evaluation of the elevated plus-maze and open-field tests for the assessment of anxiety-related behaviour in inbred mice. Behav Brain Res 134: 49-57.

Carter RJ, Morton J, Dunnett SB. 2001. Motor coordination and balance in rodents. Curr Protoc Neurosci. Chapter 8: Unit 812.

Choleris E, Thomas AW, Kavaliers M, Prato FS. 2001. A detailed ethological analysis of the mouse open field test: effects of diazepam, chlordiazepoxide and an extremely low frequency pulsed magnetic field. Neurosci Biobehav Rev 25: 235-260.

Collingridge GL, Isaac JT, Wang YT. 2004. Receptor trafficking and synaptic plasticity. Nat Rev Neurosci 5: 952-962.

Deng P-Y, Rotman Z, Blundon Jay A, Cho Y, Cui J, Cavalli V, Zakharenko Stanislav S, Klyachko Vitaly A. 2013. FMRP regulates neurotransmitter release and synaptic information transmission by modulating action potential duration via BK channels. Neuron 77: 696-711.

D'Hooge R, Nagels G, Franck F, Bakker CE, Reyniers E, Storm K, Kooy RF, Oostra BA, Willems PJ, De Deyn PP. 1997. Mildly impaired water maze performance in male Fmr1 knockout mice. Neuroscience 76: 367-376.

Dobkin C, Rabe A, Dumas R, El Idrissi A, Haubenstock H, Ted Brown W. 2000. Fmr1 knockout mouse has a distinctive strain-specific learning impairment. Neuroscience 100: 423-429.

Dryer SE. 1994. $\mathrm{Na}^{+}$-activated $\mathrm{K}^{+}$channels: a new family of large-conductance ion channels. Trends Neurosci 17: 155-160.

The Dutch-Belgian Fragile X Consortium; Bakker CE, Verheij C, Willemsen R, van der Helm R, Oerlemans F, Vermey M, Bygrave A, Hoogeveen A, Oostra BA, et al. 1994. Fmr1 knockout mice: a model to study fragile $\mathrm{X}$ mental retardation. Cell 78: $23-33$.

Errico F, Nistico R, Palma G, Federici M, Affuso A, Brilli E, Topo E, Centonze D, Bernardi G, Bozzi Y, et al. 2008. Increased levels of d-aspartate in the hippocampus enhance LTP but do not facilitate cognitive flexibility. Mol Cell Neurosci 37: 236-246.

Francis DD, Zaharia MD, Shanks N, Anisman H. 1995. Stress-induced disturbances in Morris water-maze performance: interstrain variability. Physiol Behav 58: 57-65.

Gould T, Dao D, Kovacsics C. 2009. The open field test. In Mood and anxiety related phenotypes in mice (ed. Gould TD), Vol. 42, pp. 1-20. Humana Press, Totowa, NJ.

Gross C, Yao X, Pong DL, Jeromin A, Bassell GJ. 2011. Fragile X mental retardation protein regulates protein expression and mRNA translation of the potassium channel Kv4.2. J Neurosci 31: 5693-5698.

Guglielmi L, Servettini I, Caramia M, Catacuzzeno L, Franciolini F, D'Adamo MC, Pessia M. 2015. Update on the implication of potassium channels in autism: $\mathrm{K}^{+}$channelautism spectrum disorder. Front Cell Neurosci 9: 34 .

Hage TA, Salkoff L. 2012. Sodium-activated potassium channels are functionally coupled to persistent sodium currents. J Neurosci 32: $2714-2721$.
Haimann C, Magistretti J, Pozzi B. 1992. Sodium-activated potassium current in sensory neurons: a comparison of cell-attached and cell-free single-channel activities. Pflugers Arch 422: 287-294.

Harris BZ, Lim WA. 2001. Mechanism and role of PDZ domains in signaling complex assembly. J Cell Sci 114: 3219-3231.

Harrison FE, Reiserer RS, Tomarken AJ, McDonald MP. 2006. Spatial and nonspatial escape strategies in the Barnes maze. Learn Mem 13: 809-819.

Harrison FE, Hosseini AH, McDonald MP. 2009. Endogenous anxiety and stress responses in water maze and Barnes maze spatial memory tasks. Behav Brain Res 198: 247-251.

Heron SE, Smith KR, Bahlo M, Nobili L, Kahana E, Licchetta L, Oliver KL, Mazarib A, Afawi Z, Korczyn A, et al. 2012. Missense mutations in the sodium-gated potassium channel gene KCNT1 cause severe autosoma dominant nocturnal frontal lobe epilepsy. Nat Genet 44: 1188-1190.

Igelström KM. 2012. Is slack an intrinsic seizure terminator? Neuroscientist 19: $248-254$.

Joiner WJ, Tang MD, Wang LY, Dworetzky SI, Boissard CG, Gan L, Gribkoff VK, Kaczmarek LK. 1998. Formation of intermediate-conductance calcium-activated potassium channels by interaction of Slack and Slo subunits. Nat Neurosci 1: 462-469.

Kaczmarek LK. 2013. Slack, slick and sodium-activated potassium channels. ISRN Neurosci 2013: 354262.

Katz LC, Shatz CJ. 1996. Synaptic activity and the construction of cortical circuits. Science 274: 1133-1138.

Kim GE, Kaczmarek LK. 2014. Emerging role of the KCNT1 Slack channel in intellectual disability. Front Cell Neurosci 8: 209.

Kim J-I, Lee H-R, Sim S-e, Baek J, Yu N-K, Choi J-H, Ko H-G, Lee Y-S, Park S-W, Kwak C, et al. 2011. PI3K[ $\gamma]$ is required for NMDA receptor-dependent long-term depression and behavioral flexibility. Nat Neurosci 14: 1447-1454.

Kim GE, Kronengold J, Barcia G, Quraishi IH, Martin HC, Blair E, Taylor JC, Dulac O, Colleaux L, Nabbout R, et al. 2014. Human slack potassium channel mutations increase positive cooperativity between individual channels. Cell Rep 9: 1661-1672.

Koopmans G, Blokland A, van Nieuwenhuijzen P, Prickaerts J. 2003. Assessment of spatial learning abilities of mice in a new circular maze. Physiol Behav 79: 683-693.

Kooy RF. 2003. Of mice and the fragile X syndrome. Trends Genet 19: 148-154.

Krug M, Lossner B, Ott T. 1984. Anisomycin blocks the late phase of long-term potentiation in the dentate gyrus of freely moving rats. Brain Res Bull 13: 39-42.

Lee HY, Jan LY. 2012. Fragile X syndrome: mechanistic insights and therapeutic avenues regarding the role of potassium channels. Curr Opin Neurobiol 22: 887-894.

Lee HY, Ge WP, Huang W, He Y, Wang GX, Rowson-Baldwin A, Smith SJ, Jan YN, Jan LY. 2011. Bidirectional regulation of dendritic voltage-gated potassium channels by the fragile $\mathrm{X}$ mental retardation protein. Neuron 72: $630-642$.

Lockridge A, Yuan LL. 2011. Spatial learning deficits in mice lacking A-type $\mathrm{K}^{+}$channel subunits. Hippocampus 21: 1152-1156.

Lu R, Bausch AE, Kallenborn-Gerhardt W, Stoetzer C, Debruin N, Ruth P, Geisslinger G, Leffler A, Lukowski R, Schmidtko A. 2015. Slack channels expressed in sensory neurons control neuropathic pain in mice. $J$ Neurosci 35: 1125-1135.

Malenka RC, Bear MF. 2004. LTP and LTD: an embarrassment of riches. Neuron 44: 5-21.

Martin HC, Kim GE, Pagnamenta AT, Murakami Y, Carvill GL, Meyer E, Copley RR, Rimmer A, Barcia G, Fleming MR, et al. 2014. Clinical whole-genome sequencing in severe early-onset epilepsy reveals new genes and improves molecular diagnosis. Hum Mol Genet 23: 3200-3211.

Matthews EA, Weible AP, Shah S, Disterhoft JF. 2008. The BK-mediated fAHP is modulated by learning a hippocampus-dependent task. Proc Natl Acad Sci 105: 15154-15159.

Mills F, Bartlett TE, Dissing-Olesen L, Wisniewska MB, Kuznicki J, Macvicar BA, Wang YT, Bamji SX. 2014. Cognitive flexibility and long-term depression (LTD) are impaired following beta-catenin stabilization in vivo. Proc Natl Acad Sci 111: 8631-8636.

Moy SS, Nadler JJ, Young NB, Nonneman RJ, Grossman AW, Murphy DL, D'Ercole AJ, Crawley JN, Magnuson TR, Lauder JM. 2009. Social approach in genetically engineered mouse lines relevant to autism. Genes Brain Behav 8: 129-142.

Nanou E, El Manira A. 2007. A postsynaptic negative feedback mediated by coupling between AMPA receptors and $\mathrm{Na}^{+}$-activated $\mathrm{K}^{+}$channels in spinal cord neurones. Eur J Neurosci 25: 445-450.

Nanou E, Kyriakatos A, Bhattacharjee A, Kaczmarek LK, Paratcha G, El Manira A. 2008. $\mathrm{Na}^{+}$-mediated coupling between AMPA receptors and $\mathrm{K}_{\mathrm{Na}}$ channels shapes synaptic transmission. Proc Natl Acad Sci 105: 20941-20946. 
Nicholls RE, Alarcon JM, Malleret G, Carroll RC, Grody M, Vronskaya S, Kandel ER. 2008. Transgenic mice lacking NMDAR-dependent LTD exhibit deficits in behavioral flexibility. Neuron 58: 104-117.

Nielsen DM, Derber WJ, McClellan DA, Crnic LS. 2002. Alterations in the auditory startle response in Fmr1 targeted mutant mouse models of fragile X syndrome. Brain Res 927: 8-17.

Padmashri R, Reiner BC, Suresh A, Spartz E, Dunaevsky A. 2013. Altered structural and functional synaptic plasticity with motor skill learning in a mouse model of fragile X syndrome. J Neurosci 33: 19715-19723.

Paradee W, Melikian HE, Rasmussen DL, Kenneson A, Conn PJ, Warren ST. 1999. Fragile X mouse: strain effects of knockout phenotype and evidence suggesting deficient amygdala function. Neuroscience $\mathbf{9 4 :}$ $185-192$.

Peier AM, McIlwain KL, Kenneson A, Warren ST, Paylor R, Nelson DL. 2000. (Over)correction of FMR1 deficiency with YAC transgenics: behavioral and physical features. Hum Mol Genet 9: 1145-1159.

Pfeiffer BE, Huber KM. 2009. The state of synapses in fragile X syndrome. Neuroscientist 15: 549-567.

Pietropaolo S, Guilleminot A, Martin B, D'Amato FR, Crusio WE. 2011. Genetic-background modulation of core and variable autistic-like symptoms in Fmr1 knock-out mice. PLoS One 6: e17073.

Prut L, Belzung C. 2003. The open field as a paradigm to measure the effects of drugs on anxiety-like behaviors: a review. Eur I Pharmacol 463: 3-33.

Roozendaal B, McEwen BS, Chattarji S. 2009. Stress, memory and the amygdala. Nat Rev Neurosci 10: 423-433.

Roy S, Zhao Y, Allensworth M, Farook MF, LeDoux MS, Reiter LT, Heck DH. 2011. Comprehensive motor testing in Fmr1-KO mice exposes temporal defects in oromotor coordination. Behav Neurosci 125: 962-969.

Ruffin VA, Gu XQ, Zhou D, Douglas RM, Sun X, Trouth CO, Haddad GG. 2008. The sodium-activated potassium channel Slack is modulated by hypercapnia and acidosis. Neuroscience 151: 410-418.

Sakata K, Martinowich K, Woo NH, Schloesser RJ, Jimenez DV, Ji Y, Shen L, Lu B. 2013. Role of activity-dependent BDNF expression in hippocampal-prefrontal cortical regulation of behavioral perseverance. Proc Natl Acad Sci 110: 15103-15108.

Santi CM, Ferreira G, Yang B, Gazula VR, Butler A, Wei A, Kaczmarek LK, Salkoff L. 2006. Opposite regulation of Slick and Slack $\mathrm{K}^{+}$channels by neuromodulators. I Neurosci 26: 5059-5068.

Sausbier M, Hu H, Arntz C, Feil S, Kamm S, Adelsberger H, Sausbier U, Sailer CA, Feil R, Hofmann F, et al. 2004. Cerebellar ataxia and Purkinje cell dysfunction caused by $\mathrm{Ca}^{2+}$-activated $\mathrm{K}^{+}$channel deficiency. Proc Natl Acad Sci 101: 9474-9478.

Sausbier U, Sausbier M, Sailer CA, Arntz C, Knaus HG, Neuhuber W, Ruth P. 2006. $\mathrm{Ca}^{2+}$-activated $\mathrm{K}^{+}$channels of the BK-type in the mouse brain. Histochem Cell Biol 125: 725-741.

Serrano P, Friedman EL, Kenney J, Taubenfeld SM, Zimmerman JM, Hanna J, Alberini C, Kelley AE, Maren S, Rudy JW, et al. 2008. PKMzeta maintains spatial, instrumental, and classically conditioned long-term memories. PLoS Biol 6: 2698-2706.

Tamsett TJ, Picchione KE, Bhattacharjee A. 2009. NAD ${ }^{+}$activates $\mathrm{K}_{\mathrm{Na}}$ channels in dorsal root ganglion neurons. J Neurosci 29: 5127-5134.

Thuault SJ, Malleret G, Constantinople CM, Nicholls R, Chen I, Zhu J, Panteleyev A, Vronskaya S, Nolan MF, Bruno R, et al. 2013. Prefrontal cortex HCN1 channels enable intrinsic persistent neural firing and executive memory function. J Neurosci 33: 13583-13599.
Typlt M, Mirkowski M, Azzopardi E, Ruettiger L, Ruth P, Schmid S. 2013. Mice with deficient BK channel function show impaired prepulse inhibition and spatial learning, but normal working and spatial reference memory. PLoS One 8: e81270.

Uchino S, Wada H, Honda S, Hirasawa T, Yanai S, Nakamura Y, Ondo Y, Kohsaka S. 2003. Slo2 sodium-activated $\mathrm{K}^{+}$channels bind to the PDZ domain of PSD-95. Biochem Biophys Res Commun 310: 1140-1147.

Udagawa T, Farny NG, Jakovcevski M, Kaphzan H, Alarcon JM, Anilkumar S, Ivshina M, Hurt JA, Nagaoka K, Nalavadi VC, et al. 2013. Genetic and acute CPEB1 depletion ameliorate fragile X pathophysiology. Nat Med 19: 1473-1477.

Van Dam D, D'Hooge R, Hauben E, Reyniers E, Gantois I, Bakker CE, Oostra BA, Kooy RF, De Deyn PP. 2000. Spatial learning, contextual fear conditioning and conditioned emotional response in Fmr1 knockout mice. Behav Brain Res 117: 127-136.

Vianna MR, Igaz LM, Coitinho AS, Medina JH, Izquierdo I. 2003. Memory extinction requires gene expression in rat hippocampus. Neurobiol Learn Mem 79: 199-203.

Vorhees CV, Williams MT. 2006. Morris water maze: procedures for assessing spatial and related forms of learning and memory. Nat Protoc 1: $848-858$.

Williams MT, Morford LL, Wood SL, Wallace TL, Fukumura M, Broening HW, Vorhees CV. 2003. Developmental

D-methamphetamine treatment selectively induces spatial navigation impairments in reference memory in the Morris water maze while sparing working memory. Synapse 48: 138-148.

Yan QJ, Asafo-Adjei PK, Arnold HM, Brown RE, Bauchwitz RP. 2004. A phenotypic and molecular characterization of the fmr1-tm1Cgr Fragile X mouse. Genes Brain Behav 3: 337-359.

Yang B, Desai R, Kaczmarek LK. 2007. Slack and Slick K(Na) channels regulate the accuracy of timing of auditory neurons. J Neurosci 27: 2617-2627.

Yu H, Wang DD, Wang Y, Liu T, Lee FS, Chen ZY. 2012. Variant brain-derived neurotrophic factor Val66Met polymorphism alters vulnerability to stress and response to antidepressants. J Neurosci 32: 4092-4101.

Yuan A, Santi CM, Wei A, Wang ZW, Pollak K, Nonet M, Kaczmarek L, Crowder CM, Salkoff L. 2003. The sodium-activated potassium channel is encoded by a member of the Slo gene family. Neuron 37: 765-773.

Zhang M, Wang H. 2013. Mice overexpressing type 1 adenylyl cyclase show enhanced spatial memory flexibility in the absence of intact synaptic long-term depression. Learn Mem 20: 352-357.

Zhang M, Storm DR, Wang H. 2011. Bidirectional synaptic plasticity and spatial memory flexibility require $\mathrm{Ca}^{2+}$-stimulated adenylyl cyclases. J Neurosci 31: 10174-10183.

Zhang Y, Brown MR, Hyland C, Chen Y, Kronengold J, Fleming MR, Kohn AB, Moroz LL, Kaczmarek LK. 2012. Regulation of neuronal excitability by interaction of fragile $\mathrm{x}$ mental retardation protein with slack potassium channels. J Neurosci 32: 15318-15327.

Zhang Y, Bonnan A, Bony G, Ferezou I, Pietropaolo S, Ginger M, Sans N, Rossier J, Oostra B, LeMasson G, et al. 2014. Dendritic channelopathies contribute to neocortical and sensory hyperexcitability in Fmr1-/y mice. Nat Neurosci 17: 1701-1709.

Received December 8, 2014; accepted in revised form May 5, 2015. 


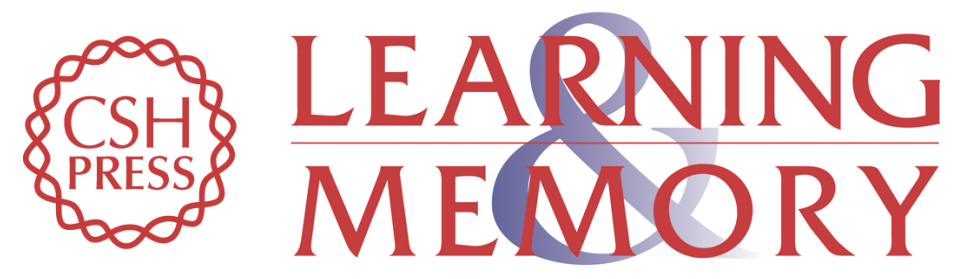

\section{The sodium-activated potassium channel Slack is required for optimal cognitive flexibility in mice}

Anne E. Bausch, Rebekka Dieter, Yvette Nann, et al.

Learn. Mem. 2015, 22:

Access the most recent version at doi:10.1101//m.037820.114

\section{Supplemental http://learnmem.cshlp.org/content/suppl/2015/06/12/22.7.323.DC1 Material}

References This article cites 89 articles, 22 of which can be accessed free at: http://learnmem.cshlp.org/content/22/7/323.full.html\#ref-list-1

Creative This article is distributed exclusively by Cold Spring Harbor Laboratory Press for the Commons first 12 months after the full-issue publication date (see

License http://learnmem.cshlp.org/site/misc/terms.xhtml). After 12 months, it is available under a Creative Commons License (Attribution-NonCommercial 4.0 International), as described at http://creativecommons.org/licenses/by-nc/4.0/.

Email Alerting Receive free email alerts when new articles cite this article - sign up in the box at the Service top right corner of the article or click here. 